\title{
A six year satellite-based assessment of the regional variations in aerosol indirect effects
}

\author{
T. A. Jones ${ }^{1}$, S. A. Christopher ${ }^{1,2}$, and J. Quaas ${ }^{3}$ \\ ${ }^{1}$ Earth System Science Center, UAHuntsville, Huntsville, AL, USA \\ ${ }^{2}$ Department of Atmospheric Science, UAHuntsville, Huntsville, AL, USA \\ ${ }^{3}$ Cloud-Climate Feedbacks Group, Max Planck Institute for Meteorology, Hamburg, Germany
}

Received: 29 September 2008 - Published in Atmos. Chem. Phys. Discuss.: 5 December 2008

Revised: 1 April 2009 - Accepted: 29 May 2009 - Published: 22 June 2009

\begin{abstract}
Aerosols act as cloud condensation nuclei (CCN) for cloud water droplets, and changes in aerosol concentrations have significant microphysical impacts on the corresponding cloud properties. Moderate Resolution Imaging Spectroradiometer (MODIS) aerosol and cloud properties are combined with NCEP Reanalysis data for six different regions around the globe between March 2000 and December 2005 to study the effects of different aerosol, cloud, and atmospheric conditions on the aerosol indirect effect (AIE). Emphasis is placed in examining the relative importance of aerosol concentration, type, and atmospheric conditions (mainly vertical motion) to AIE from region to region.

Results show that in most regions, AIE has a distinct seasonal cycle, though the cycle varies in significance and period from region to region. In the Arabian Sea (AS), the sixyear mean anthropogenic + dust AIE is $-0.27 \mathrm{Wm}^{-2}$ and is greatest during the summer months $\left(<-2.0 \mathrm{Wm}^{-2}\right)$ during which aerosol concentrations (from both dust and anthropogenic sources) are greatest. Comparing AIE as a function of thin $\left(\mathrm{LWP}<20 \mathrm{gm}^{-2}\right)$ vs. thick (LWP $\geq 20 \mathrm{gm}^{-2}$ ) clouds under conditions of large scale ascent or decent at $850 \mathrm{hPa}$ showed that AIE is greatest for thick clouds during periods of upward vertical motion. In the Bay of Bengal, AIE is negligible owing to less favorable atmospheric conditions, a lower concentration of aerosols, and a non-alignment of aerosol and cloud layers. In the eastern North Atlantic, AIE is weakly positive $\left(+0.1 \mathrm{Wm}^{-2}\right)$ with dust aerosol concentration being much greater than the anthropogenic or sea salt components. However, elevated dust in this region exists above the maritime cloud layers and does not have a hygroscopic coating, which occurs in AS, preventing the dust from acting as $\mathrm{CCN}$ and limiting AIE. The Western Atlantic has a large anthropogenic aerosol concentration transported from
\end{abstract}

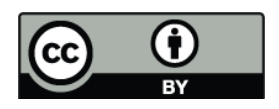

Correspondence to: T. A. Jones

(tjones@nsstc.uah.edu) the eastern United States producing a modest anthropogenic AIE $\left(-0.46 \mathrm{Wm}^{-2}\right)$. Anthropogenic AIE is also present off the West African coast corresponding to aerosols produced from seasonal biomass burning (both natural and man-made). Interestingly, atmospheric conditions are not particularly favorable for cloud formation compared to the other regions during the times where AIE is observed; however, clouds are generally thin $\left(\mathrm{LWP}<20 \mathrm{gm}^{-2}\right)$ and concentrated very near the surface. Overall, we conclude that vertical motion, aerosol type, and aerosol layer heights do make a significant contribution to AIE and that these factors are often more important than total aerosol concentration alone and that the relative importance of each differs significantly from region to region.

\section{Introduction}

Each year, approximately $140 \mathrm{Tg}$ of anthropogenic aerosols are injected into the atmosphere with $60 \%$ of these aerosols being sulfates produced from industrial pollution (Schulz et al., 2006). Aerosols often reflect incoming solar radiation back into space; thus, increasing aerosol concentrations act to cool the atmosphere, which is known as the direct effect. Fine-mode $\left(r_{a}<0.25 \mu \mathrm{m}\right)$ and sulfate based aerosols (where $r_{a}$ is the effective radius of an aerosol particle) often act as cloud condensation nuclei (CCN) for warm-process clouds (e.g. Quaas et al., 2004; Lohmann and Feichter, 2005; Penner et al., 2004; Andreae and Rosenfeld, 2009). Both observations and modeling studies have shown that as anthropogenic aerosol concentration increases, the number of $\mathrm{CCN}$ increase accordingly, leading to a decrease in liquid water cloud droplet size assuming a constant liquid water path through the cloud (e.g. Jones et al., 1994). Increasing the number of cloud droplets, increases cloud albedo, reflecting more solar radiation back into space. This is known as the

Published by Copernicus Publications on behalf of the European Geosciences Union. 
first indirect, or the Twomey effect (Twomey, 1977; Kaufman and Fraser, 1997; Feingold, 2003). The decrease in droplet size has the additional effect of delaying the onset of collision and coalescence in warm clouds, reducing precipitation efficiency and increasing cloud lifespan and possibly their areal coverage, which is labeled as the second indirect effect (Albrecht, 1989; Quaas et al., 2004). Reducing precipitation efficiency also acts to increase water loading, leading to an increase in cloud liquid water path (LWP) and a corresponding increase in cloud thickness, complicating the identification of the Twomey effect in observations (Han et al., 1998; Reid et al., 1998; Peng et al., 2002; Schwartz et al., 2002). Both the first and second indirect effects act to cool the atmosphere, possibility offsetting warming due to greenhouse gases (Lohmann and Feichter, 2005). Previous studies have estimated the total aerosol cooling effect (direct and indirect) anywhere between -0.5 to $-4.4 \mathrm{Wm}^{-2}$ from anthropogenic aerosols alone (e.g. Boucher and Lohmann, 1995) though more recent research suggests that this value is likely closer $-1.0 \mathrm{Wm}^{-2}$ (Anderson et al., 2003; Lohmann and Feichter, 2005; Forster et al., 2007; Quaas et al., 2008). However, aerosol indirect effects are highly dependent on the aerosol species, their vertical and size distribution, and meteorological conditions present at the time (e.g. Sinha et al., 2003; Patra et al., 2005; Matsui et al., 2006; Duesk et al., 2008; Yuan et al., 2008).

The following analysis primary focuses on the first aerosol indirect effect (AIE), where increasing aerosols increase $\mathrm{CCN}$, thereby reducing cloud droplet size. AIE is generally most prevelent in areas of large, thick stratus cloud decks where a high moisture content over a large region increases the probability of aerosols to act as CCN while also making observations of these effects easier from a remote sensing perspective (e.g. Nakajima et al., 1991; Feingold et al., 2003; Borg and Bennertz, 2007). Traditionally fine-mode, hygroscopic aerosols ranging in size from 70 to $200 \mathrm{~nm}$ (e.g. sulfates produced from anthropogenic sources) are considered the most efficient CCN (Jones et al., 1994; Li et al., 1996; Andreae and Rosenfeld, 2008). Over the ocean, AIEs are generally prevalent near locations of large aerosol sources, such as ship tracks and downwind of major pollution (Ackerman et al., 2003; Avey et al., 2007; Bennartz, 2007). Since the background aerosol concentration is low, AIE caused by the addition of large concentrations of anthropogenic aerosols is most noticeable over the ocean (Lohmann and Lesins, 2003; Borg and Bennartz, 2007). With the increasing $\mathrm{CCN}$, comes a decrease in water droplet size, since the available moisture is spread throughout a larger number of CCN. The resulting decrease in drop size distributions increases cloud albedo, reflecting more solar radiation back into space. Less hygroscopic aerosols such as mineral dust are less likely to combine with water vapor and become $\mathrm{CCN}$; thus, limiting their potential to change cloud albedo. However, dust aerosols can become coated with hygroscopic material in highly polluted regions, greatly increasing their ability to act as effective CCN (e.g. Levin et al., 1996; Seinfeld and Pandis, 1998; Satheesh et al., 2006).

No matter what aerosol type is present, several other conditions must be met in order for AIEs to occur. For aerosols to act as CCN, aerosols must exist at cloud base. Aerosols above the cloud layer are unlikely to act as CCN (except in circumstances where cloud-top entrainment occurs with boundary layer clouds), but can cause other changes to the environment that can also modify cloud properties. In addition, atmospheric conditions must be favorable for cloud formation. These conditions include at least some degree of uplift within the aerosol - cloud layer, sufficient moisture to activate aerosol $\mathrm{CCN}$, and sufficient temperatures for clouds to form in a warm process manner (Snider et al., 2003). (The effects of aerosols on ice $\mathrm{CCN}$ are considered outside the scope of this research). Going forward, it is important to consider that aerosol, cloud, and atmospheric conditions are all inter-related and must all be examined to determine what effects (if any) aerosols are having on clouds. These effects have been studied and quantified by several satellite, model, and in situ based research efforts, some of which are summarized below.

\subsection{Satellite based}

Using 5 years of January data, Chylek et al. (2006) observed that cloud droplet radius decreases from south to north in the Indian Ocean $\left(15^{\circ} \mathrm{S}\right.$ to $\left.25^{\circ} \mathrm{N}\right)$ corresponding to an increase in anthropogenic aerosol concentration. Jones and Christopher (2008) observed that the AIE (defined by the inverse correlation between cloud droplet effective radius and AOT) was greatest during the summer months, when dust aerosols comprise the largest portion of the total AOT. Dust aerosols are not normally considered as good CCN, but as noted previously, mineral dust has been observed to be effective CCN when coated with anthropogenic aerosols (Levin et al., 1996; Satheesh et al., 2006).

Also, Jones and Christopher (2008) observed a positive relationship between total column AOT and cloud droplet effective radius in the Arabian Sea during the Northern Hemisphere winter. Neither Jones and Christopher (2008) nor Yuan et al. (2008) could precisely determine the exact physical cause although Yuan et al. (2008) (using model comparisons) hypothesized that the increase in cloud droplet size with AOD could be related to slightly soluble organic particles and/or giant cloud condensation nuclei. Other possible causes include the changes in aerosol species and meteorological conditions that occur throughout the year in this region. Given these complications, AIE on a global scale is often difficult to observe as noted by Breon et al. (2002).

Many previous research efforts have emphasized quantifying the effect of anthropogenic (fine-mode) aerosols on cloud properties (Lohmann and Feichter, 2005; Quaas et al., 2008). While these effects are important for climate change studies, the effects of other types of aerosols must also be understood 
because the radiative forcing by an anthropogenic AIE also strongly depends on the natural background conditions (e.g., Bellouin et al., 2008). The influence of additional aerosol types, such as dust, on $\mathrm{CCN}$ and cloud characteristics has been documented, but to a lesser extent. The importance of environmental conditions to AIEs has not been ignored, but is also certainly less well documented. For example, Kaufman et al. (2005a) estimated that the effect of aerosols and independent meteorological observations to changes in cloud coverage to be roughly equal. In addition, Yuan et al. (2008) concluded that $70 \%$ of the variability between AOT and cloud droplet effective radius was due to changes in atmospheric water content, not from aerosols increasing the number of CCN. Thus, it is clear the both aerosol concentrations and the surrounding atmospheric conditions are key to the magnitude of AIE.

\subsection{Modeling based}

Another approach for examining AIE is through model simulations. However, given the complexities inherent in AIE modeling, quantifying these effects has proven a challenging endeavor. Large scale general circulation models have generally over-estimated this effect (compared to observational studies) due to inadequate droplet activation parameterizations and/or inadequate characterization of semi-direct effects, among other issues (Jones et al., 1994; Lohmann and Lesins, 2002; Anderson et al., 2003). Higher resolution models, which are better able to account for the microphysical interactions between aerosols and clouds have shown more interesting results. For example, Feingold (2003) noted that indirect effects from ammonium sulfate aerosols (commonly produced from anthropogenic sources) are significantly greater than those compared to aerosols with a lower solubility. Similarly, indirect effects were more likely to occur with air parcels originating from maritime sources due to the contribution of sea-salt aerosols. In another study, Jiang and Feingold (2006) using a large eddy simulation model investigated the effects of increases in aerosol loading on cloud properties such as LWP, cloud fraction, and droplet size. Effects of absorbing aerosols such as dust and black carbon were included in this analysis. Results showed that without radiative effects, no significant changes in cloud properties occurred as a function of aerosol loading, though precipitation did decrease. The inherent dynamical variability of the clouds was more important. If radiative effects were included, then cloud properties became highly correlated with aerosol loading. The key result of this research is that the radiative effects of aerosols may have a greater impact than the microphysical effect of just increasing $\mathrm{CCN}$.

\subsection{In situ and ground-based}

Only with in situ and ground-based studies do direct measurements of aerosol, cloud, and atmospheric conditions usu- ally exist in a relatively coincident manner. However, these studies are generally limited to small spatial and temporal scales, limiting their applicability to a larger scale. Still, these studies provide important insights into the AIE. For example, Feingold et al. (2003) observed that droplet effective radius does decrease as aerosol extinction (or AOT) increases for individual case studies using ground-based remote sensing observations from the Oklahoma ARM site. Using data from the same site, Penner et al. (2004) observed similar results. Brenguier et al. (2003) used independent measurements of cloud and aerosol properties taken during the ACE-2 campaign and found that AOT and cloud droplet size were negatively correlated for clouds of similar geometric thickness, which is consistent with the Twomey effect. However, for highly polluted situations during the campaign, the air was dryer resulting in thinner clouds and a positive relationship between AOT and droplet size. Note that this latter result is consistent with studies such as Peng et al. (2002) and Yuan et al. (2008). Several studies have analyzed the effects of smoke emanating from ship exhaust on cloud properties along ship tracks (e.g. Coakley and Walsh, 2001; Ackerman et al., 2003). For the most part, these studies observed a decrease in cloud droplet effective radius and an increase in cloud coverage along the ship tracks, consistent with the first and second indirect effects. Combining data from multiple examples (from various research efforts) using quasi-independent measurements of AOT and $\mathrm{CCN}$, Andreae (2009) concluded that an excellent relationship between AOT and CCN exists, but that uncertainties of approximately one order of magnitude also exist. Thus, it can be said that substantial evidence exists for AIEs on a case-by-case basis for a variety of aerosol and atmospheric conditions, but that a more comprehensive analysis is required to determine if results from these case studies are consistent with those observed on much larger spatial and temporal scales.

This research will apply a primarily satellite-based approach to study aerosol indirect effects. Many limitations exist in this approach, which lead to certain unavoidable ambiguities in interpretation of the data. The limitations include the lack of coincident aerosol - cloud observations, poor temporal sampling (since we use polar orbiting satellites), inadequate spatial and temporal sampling of atmospheric conditions, and the use of total column products when vertical distributions would be better suited. The lack of coincident aerosol and cloud retrievals is very important, since we then make the implicit assumption that aerosols properties in cloud-free regions are representative for those under cloudy conditions (Matheson et al., 2005; Bulgin et al., 2008; Quaas et al., 2008). The assumption is that cloud-based CCN concentrations scale with clear-sky AOT. For various clean and polluted situations, it has been shown by Andreae (2009) that indeed in-situ measured cloud base CCN concentrations are linearly related to satellite retrieved AOT. However, significant uncertainties remain. Along the edges of clouds, where the atmosphere is near saturation, hygroscopic aerosols can 


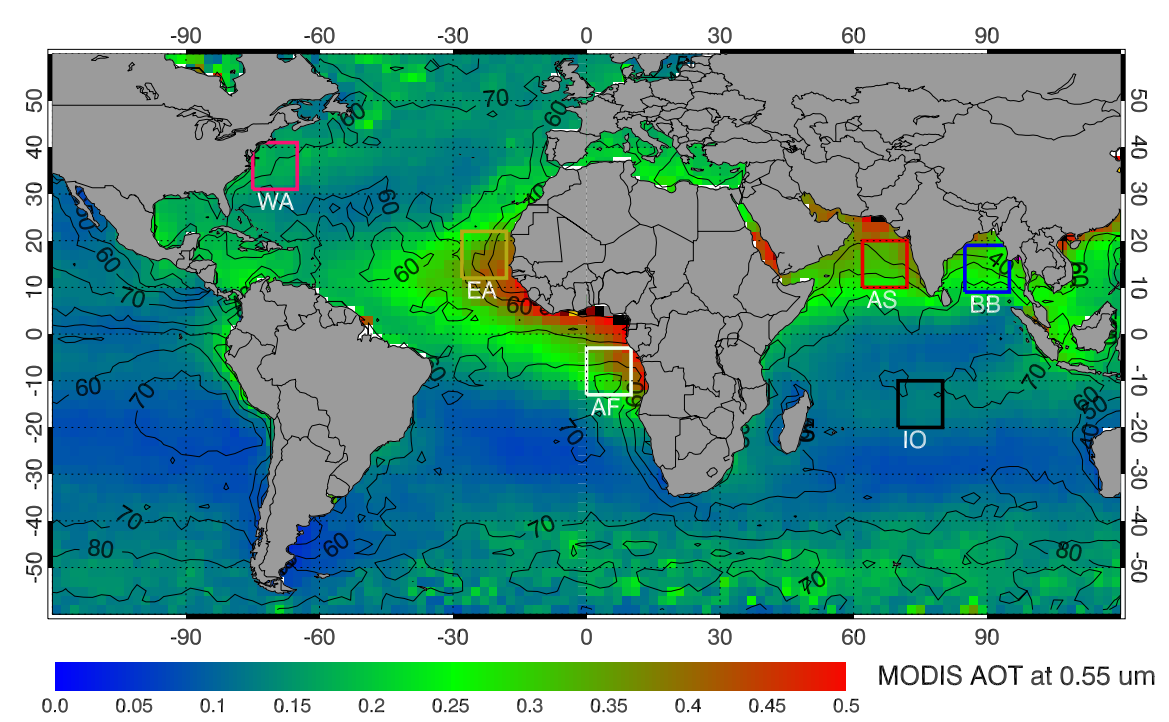

Fig. 1. Locations of study regions overlaid on globally averaged total column MODIS AOT, with contours indicating average cloud fraction $(\%)$.

grow in size, which in turn can increase retrieved AOT compared to a similar concentration of aerosols in a dry environment (Haywood et al., 1997; Feingold et al., 2003; Dusek et al., 2006; Koren et al., 2007; Su et al., 2008). Similarly, photons escaping from the side of clouds can be scattered back toward the satellite by surrounding aerosols, artificially increasing AOT (Wen et al., 2006; Marshak et al., 2008). Observational uncertainties such as these impose significant limitations on satellite-based estimates of aerosol indirect effects, which is discussed in greater detail in Sect. 2.

This research examines the hypothesis that for the first AIE to occur, that hygroscopic aerosols exist, are located in the vicinity of the cloud layer, and that atmospheric conditions are favorable for cloud development. If these conditions are not met, then aerosols are not likely to be activated into $\mathrm{CCN}$, and little indirect effect would occur. If they are met, then AIE can be quantified and studied. To accomplish this task, total column aerosol optical thickness (AOT) and cloud properties retrieved by the MODIS instrument present onboard the Terra and Aqua EOS satellites are compared with atmospheric conditions, especially humidity and vertical velocity for a detailed analysis of AIEs from an observational perspective. While using similar methods as Quaas et al. (2008), this research analyzes indirect effects of both anthropogenic and dust aerosols over a multi-year timespan while also including analysis of corresponding atmospheric conditions. A novel feature of this work is the comparison of AIE to vertical velocity, since the latter is very important to cloud formation. One of the key questions to be examined is the relative importance of aerosol concentrations (and type) and atmospheric conditions.

To evaluate the changes in the aerosol indirect effect as a function of different aerosol species and atmospheric condi- tions, we selected six $10^{\circ} \times 10^{\circ}$ regions over the ocean, each with a predominant aerosol type (Fig. 1). The North-East Atlantic Ocean (EA) and Arabian Sea (AS) are selected to study the effects of dust aerosols. Large concentrations of dust exist in both regions during the summer months providing the opportunity to analyze its effects on cloud properties. However, anthropogenic aerosols still account for the majority of aerosols in this region. Anthropogenic aerosols from pollution sources are located nearly year-round in the Bay of Bengal (BB), and the Northwest Atlantic (WA). They are also the dominant aerosol type in the Arabian Sea during the winter months. Large concentrations of carbonaceous anthropogenic aerosols are present in the South Atlantic off Southeast Africa (AF) resulting from biomass burning on the African continent, and we include this region in our analysis. Finally, a relatively pristine region in the Southern Indian Oceans (IO) that primarily comprises of maritime sea salt is examined to assess indirect effects when overall aerosol concentrations are low.

AIE due to fine mode (primarily anthropogenic) and dust aerosols for each region are calculated using daily Terra Moderate Resolution Imaging Spectroradiometer (MODIS) aerosol and cloud product over a 6-year period (2000-2006) contained within the Clouds and the Earth's Radiant Energy System (CERES) data in the CERES Single Scanner Footprint (SSF) product. Using this long-term data set, it is possible not only to compare indirect effects between regions, but also analyze how these effects change as a function of time. Each region has its own unique aerosol and meteorological properties, which are key to understanding the relative importance of aerosol properties and atmospheric conditions. For comparison, anthropogenic dust aerosol direct radiative effects are also calculated to provide 
a comprehensive overview of the aerosol-cloud radiative effects for each region. Using Multi-Angle Imaging Spectroradiometer (MISR) Stereo Height data, Total Ozone Mapping Spectrometer (TOMS) aerosol index (AI), and CALIPSO aerosol layer heights, the importance of the vertical profiles of both aerosols and clouds relative to AIE is demonstrated through selected examples.

\section{Data}

\subsection{Cloud properties}

The Clouds and Earth's Radiant Energy System (CERES) Single Scanner Footprint (SSF) FM1, Edition 2B data between March 2000 and December 2005 from the Terra satellite (on a sun-synchronous orbit with an equator-crossing local time of about 10:30 a.m.) were collected for the six $10 \times 10^{\circ}$ regions over the ocean (Fig. 1). Each region represents a unique aerosol - climate regime where AIEs are likely to differ. The six regions chosen are the Arabian Sea $\left(10-20^{\circ} \mathrm{N} ; 62-72^{\circ} \mathrm{E}\right)$, Bay of Bengal $\left(9-19^{\circ} \mathrm{N} ; 85-95^{\circ} \mathrm{E}\right)$, South Indian Ocean $\left(10-20^{\circ} \mathrm{S} ; 70-80^{\circ} \mathrm{E}\right)$, Eastern North Atlantic $\left(10-20^{\circ} \mathrm{N} ; 18-28^{\circ} \mathrm{W}\right)$, Western North Atlantic (31$\left.41^{\circ} \mathrm{N}, 65-75^{\circ} \mathrm{W}\right)$, and the Eastern South Atlantic $\left(3-13^{\circ} \mathrm{S}\right.$; $\left.0-10^{\circ} \mathrm{E}\right)$. The CERES-SSF product combines the radiative fluxes retrieved from the CERES instrument with aerosol properties from the MOD04 (Collection 4) product (Remer et al., 2005) and cloud properties (Minnis et al., 2003) retrieved from MODIS. At nadir, CERES-SSF footprint resolution is $\sim 20 \mathrm{~km}$ with a near daily global coverage. Cloud properties include cloud liquid water path (LWP), water cloud effective droplet radii $\left(R_{c}\right)$, cloud optical thickness (COT), and cloud top pressure (CTP) retrieved from the $3.7 \mu \mathrm{m}$ (mid-IR) channel (Minnis et al., 2003). For adiabatically stratified water clouds, the theoretical relationship between $R_{c}$ and LWP is described by Eq. (1) where $\rho$ is the density of liquid water and $\tau_{c}$ is cloud layer optical depth (e.g. Wood and Hartmann, 2006).

$\mathrm{LWP}=\frac{5}{9} \rho \tau_{c} R_{c}$

MODIS is capable of resolving cloud characteristics at 2 different levels, one nearer to the surface, the other (if it exists) higher in the atmosphere. However, the primary focus of this study is liquid water clouds, so only data from the lower cloud layer are considered. Averaged over all regions, this lower cloud layer lies on average near $837 \mathrm{hPa}$, which it approximately 1.5 to $2 \mathrm{~km}$ a.s.l., well below the freezing level $\left(0^{\circ} \mathrm{C}\right)$ located around $5 \mathrm{~km}$ a.g.l. For comparison, the second cloud layer lies near $680 \mathrm{hPa}$, but this cloud layer is only retrieved for less than $5 \%$ of all cloud observations. Since the second cloud layer is comparatively rare, and since we choose to only investigate AIE on low-level liquid water clouds, data associated with the upper cloud layer are removed. The MODIS algorithm over oceans uses visible to near-IR wavelengths to retrieve cloud optical depth and near IR to mid-IR measurements to retrieve cloud droplet size that are then converted to LWP using Eq. (1). The only constraints placed on the data (outside normal quality control flags) is that MODIS cloud data are only used for pixels over water surfaces and when the MODIS cloud-phase parameter indicates that the cloud in question is at least $95 \%$ or more comprised of liquid water droplets. Potential effects of aerosols on ice clouds are beyond the scope of this study. Compared to the cloud retrieval in the MOD06 product (Platnick et al., 2003), CERES-SSF generally produces smaller cloud droplet size and cloud optical thickness (COT) values, though the overall patterns are generally similar with overall cloud amounts differing less than 10\% (Minnis et al., 2003).

Han et al. (1994) and more recently Platnick et al. (2003) provide a review of the various error sources in the retrieval process including calibration, assumptions in atmospheric and surface properties, ambiguous solutions for optically thin clouds, calibration, vertical inhomogeneity of clouds and cirrus contamination. One significant uncertainty related to this research is the uncertainty associated with optically thin clouds (e.g. Nakajima and King, 1990). Under these circumstances, the relationship between retrieved COT and cloud droplet effective radius may be ambiguous. However, we cannot ignore optically thin clouds as part of this research as they contribute a large portion of the total cloud cover for some regions at certain times of the year (Turner et al., 2007; Jones and Christopher, 2008). Turner et al. (2007) in particular noted that changes in aerosol concentration can have significant effects to cloud liquid water content and the occurrence of precipitation. To address the importance of thin clouds on AIE in the context of this research, the results are split into thin $\left(\mathrm{LWP}<20 \mathrm{gm}^{-2}\right)$ and thick (LWP $\geq 20 \mathrm{gm}^{-2}$ ) samples while noting that greater certainty exists with aerosol - cloud relationships in the thick cloud sample.

In addition to using cloud-top pressure to determine cloud top height, this research also examines cloud layer height using the MISR Stereo height product (Moroney et al., 2002; Kahn et al., 2007). This product identifies cloud (or thick aerosol) layers by stereo-matching images from MISR's nadir camera with those from cameras observing at more oblique angles up to $70^{\circ}$. Using observations of the same feature from multiple viewing angles, it is possible to solve for the approximate height of that layer to within $\pm 200 \mathrm{~m}$. The result is a map of either cloud layer or aerosol layer heights for a given MISR swath, which can then be compared to the independent cloud property retrievals. Several examples of MISR data are examined where both significant aerosol and cloud concentrations exist to better assess the importance of vertical profiles relative to AIE. 


\subsection{Aerosol properties}

Cloud properties are combined with MODIS derived aerosol optical thickness (AOT) and fine mode fraction (FMF) at $0.55 \mu \mathrm{m}$ wavelength. MODIS products are derived from cloud-free $500 \mathrm{~m}$ resolution data and aggregated to a $10 \mathrm{~km}$ footprint $(20 \times 20$ pixels $)$ used by the MODIS level 2 aerosol product (MOD04). At least 10 pixels must remain (2.5\%) after cloud masking and other quality control procedures for an aerosol retrieval to be made. The nature of the cloud masking algorithm used by MODIS is such that it tends to classify very thick aerosol layers (i.e. dust over the North Atlantic) as clouds and not aerosols (Remer et al., 2005). As a result, total AOT may be somewhat underestimated. If a retrieval is made, the $10 \mathrm{~km}$ parameters are then converted to match the CERES $20 \mathrm{~km}$ field of view (FOV) using a point spread weighting function (Loeb et al., 2005). Both "average" and "best" AOT retrievals are included in the CERES-SSF AOT.

The accuracy of the MODIS AOT product over oceans is $\pm 0.03 \pm 0.05 \tau$ (Remer et al., 2005) with the uncertainty for the FMF being on the order of 30\% (Kleidmann et al., 2006). FMF is a measure of aerosol size with large values of FMF indicating mostly fine-mode (e.g. largely anthropogenic) aerosols present, and low values indicating mostly coarse-mode (e.g. coarse sea salt and/or mineral dust) present (Kaufman et al., 2005b, c). FMF is used as a tool to determine the effect of aerosol type on cloud properties. We must also note that the CERES-SSF product used here (Edition 2B) only contains Collection 4 aerosol parameters. Fortunately, differences between Collection 4 and 5 over the oceans are relatively small and should not impact the result presented here (Remer et al., 2005). MODIS cloud fraction over ocean is converted to the CERES FOV using the same procedure. The MODIS cloud masking algorithm uses spatial variability tests along with visible and infrared brightness tests to identify clouds (Martins et al., 2002; Remer et al., 2005). Cloud fraction ranges from 0 (indicating completely clear) to 1.0 , indicating totally cloudy scenes.

While the MODIS algorithm uses strict cloud-clearing thresholds when calculating AOT, some cloud contamination does remain (Remer et al., 2005; Zhang and Reid, 2006; Yuan et al., 2008). Some aerosols species, such as sea salt and sulfate, are hygroscopic and will grow in size in high humidity environments, which are present in the vicinity of clouds (Feingold et al., 2003; Jeong et al., 2007; Su et al., 2008). Thus, the same aerosol concentrations will produce higher visible and near infrared reflectances near clouds since the aerosols have swelled in size due to the moisture. When this occurs, AOT is overestimated in the vicinity of clouds when partly cloudy conditions exist within a MODIS pixel, which in turn would lead to an over-estimation of AIE though a false inverse correlation of AOT and $R_{c}$ (Koren et al., 2007). The magnitude of this increase has been estimated to be $13 \%$ and $11 \%$ for visible wavelengths when comparing against AERONET and MODIS data (Koren et al., 2007).
Similarly, Su et al. (2008) observed an increase in AOT up to $17 \%$ in the vicinity of clouds compared to independent measurements from lidar data. The increase was measured on spatial scales from 100 to $5000 \mathrm{~m}$ from the cloud edge and was attributed primarily to an increase in aerosol size in high humidity environments. If this increase in AOT is a result of an increase in aerosol size, then parameters such Angstrom exponent and FMF should also be sensitive to cloud coverage (Kaufman et al., 2005a; Redemann et al., 2009). Koren et al. (2007) observed lower Angstrom exponent values near clouds, and attributed these values to larger, humidified aerosols and/or small cloud droplets being improperly identified as aerosols. Another important consideration is that scattering from nearby clouds may also lead to spuriously high AOT retrievals (Wen et al., 2006; Marshak et al., 2008). However, Wen et al. (2006) observed that this phenomena is only occurs on a spatial scale of up to a few kilometers. Since MODIS derives AOT at $10 \mathrm{~km}$ (and we use AOT data that has been remapped to a $20 \mathrm{~km}$ resolution), this effect should not be resolvable in the MODIS data used here and should not significantly impact the interpretation of the results.

An increase in aerosol size near clouds may also significantly affect whether or not this research classifies the AIE as dust or anthropogenic. Sulfate aerosols are assumed to be mostly fine-mode and anthropogenic. However, under some circumstances, anthropogenic aerosols can be larger and when this occurs anthropogenic AIE will be falsely classified as dust AIE. Since this distinction has never been attempted previously from an observational perspective, the relative magnitude of anthropogenic vs. dust AIE must be considered highly uncertain. (More confidence does exist in the combined dust + anthropogenic values).

Another important consideration is that certain meteorological conditions can lead to both an increase in AOT and cloud fraction, which cloud lead to a false indicator of AIE. For example, Mauger and Norris (2007) noted that the dependence of cloud fraction on AOT was reduced by over $50 \%$ when low-level (700-1000 hPa) static stability from upwind parcels was taken into account. They found that for stratiform clouds in the Northeastern Atlantic, high AOT and cloud fraction was associated with high static stability conditions $48 \mathrm{~h}$ prior upwind of the AOT and cloud fraction observations. As a result, the time-lag between certain atmospheric conditions and AOT can account for a non-trivial amount of AOT vs. cloud property correlations when only similar-time observations are compared. Since it was not possible to use such a time-lag analysis for the data used in this research, in part due to the uncertainty introduced be the $2.5^{\circ}$ resolution of the NCEP Reanalysis product. As a result, we note that upwind meteorological conditions are affected both AOT and cloud properties possibly leading to an over estimation of AIE given the significant correlation between high AOT and cloud fraction with upstream static stability. However, we do make comparisons between instantaneous observations of AOT and vertical velocity, the latter of which 
should be a response to the atmospheric conditions advected into a region at any one time. If this is indeed occurring, AIE may be somewhat over estimated for thick clouds occurring during sustained upward motion.

The net result of these observational biases is an increased correlation between AOT and COT, leading to an overestimation of AIE through either anomalously high AOT retrievals and/or the impacts of upstream atmospheric conditions. In an ideal scenario, the uncertainty in AOT could be reduced by removing MODIS pixels with a cloud fraction greater than some value. However, by doing this, we remove data associated with some of the highest aerosol concentrations and thickest clouds, where AIE are most likely to be observed. For all regions, well over $50 \%$ of the data correspond to cloud fractions of $50 \%$ or greater (Fig. 2a). Removing these data would introduce an unacceptable sampling bias to the results. Instead, we use all available AOT data and note that uncertainties due to clouds may account for some portion of the correlation in aerosol and cloud properties.

Bulgin et al. (2008) makes the assumption that aerosol observations in the vicinity of clouds are adequate in lieu of coincident observations when averaged over large spatial $\left(1^{\circ}\right)$ and temporal (seasonal) scales. Despite this assumption not being completely accurate, the resulting overestimation of AIE was deemed small. Since truly independent measurements of aerosol and cloud properties using satellite-based methods are not practical, we too make the same assumption and note the resulting uncertainty it introduces. Further evidence for the validity of this assumption was presented by Andreae (2009). To assess the impacts of near cloud biases in AOT and FMF in this research, both values are analyzed as a function of MODIS cloud fraction for each region. For cloud fractions greater than $60 \%$, a positive relationship exists between cloud fraction and AOT for all regions except BB (Fig. 2b). The average increase in AOT between cloud fractions of $60 \%$ and $100 \%$ is approximately 0.1 over the AOT when cloud fraction is less than $60 \%$. Interestingly, this increase is about the same irrespective of the AOT values at low cloud fractions.

Several factors may be responsible for the increase in AOT. First, larger concentrations of aerosols may be indeed present near clouds, which would be consistent with indirect theory. However, it may also be possible that AOT is higher because of the increase in size of humidified aerosols near clouds as discussed previously. It is likely both are simultaneously being observed here. To determine what impact the change in aerosol size is having, MODIS FMF is also plotted against cloud fraction (Fig. 2c). For all regions except IO and EA, a small decrease in FMF occurs as cloud fraction increases. The lower FMF values are evidence for the larger humidified aerosols expected in the vicinity of clouds. However, the change in FMF from 0 to $100 \%$ cloud fraction is less than $15 \%$ (except for IO, where FMF increases as a function of cloud fraction). In the eastern North Atlantic mineral dust represents the primary aerosol type, which is

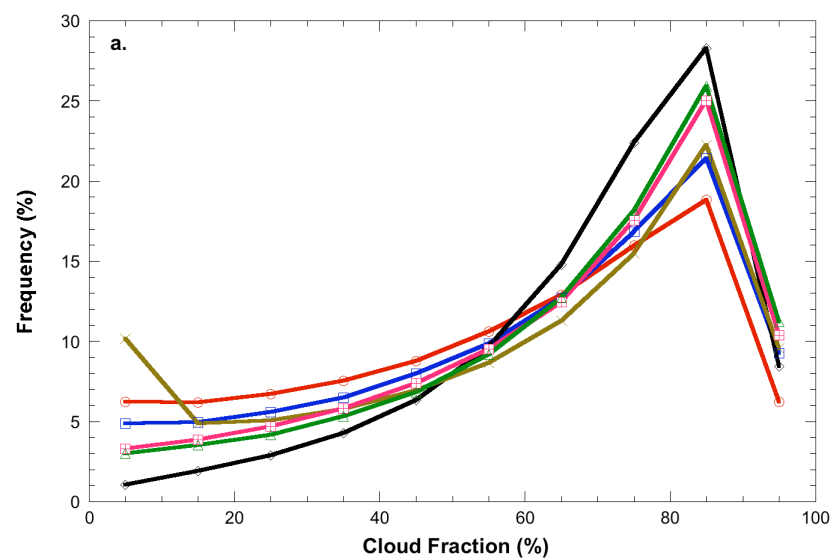

Fig. 2. Frequency (a), aerosol optical thickness (b), and fine mode fraction (c), binned as a function of MODIS cloud fraction for each region of study. Note that the maximum number of pixels occur when cloud fraction is approximately $80 \%$. AOT increases as a function of cloud fraction due to both hygroscopic aerosol growth and indirect effects. FMF decreases approximately $15 \%$ for all regions except EA, where change is minimal, and IO where an increase is present.

generally non-hygroscopic. As a result, FMF would not be expected to decrease as a function of cloud fraction, at in fact remains nearly constant. The increase in FMF relative to cloud fraction in IO occurs as a result of small concentrations of fine mode aerosols (either anthropogenic or DMS) being present on top of the natural sea-salt background and/or possible nucleation of sulfate particles through aqueous chemistry. Since AOT is higher in these circumstances, AIEs and increased cloud cover is more likely. For the other regions, the differences in FMF are generally less than the relative change in AOT as a function of cloud fraction indicating that at least a portion of these changes is due to other factors beside humidified aerosol growth. Thus, when changes in aerosol and cloud properties exceed $15 \%$, then it is likely either AIE and/or atmospheric conditions are affecting the interaction between aerosol and cloud properties.

The TOMS or OMI instruments can also be used to study aerosol concentration and type using ultra-violet (UV) observations and have the advantage of not being as sensitive to cloud contamination (Hsu et al., 2000). In particular, dust and biomass burning aerosols absorb radiation at UV wavelengths when compared to a clear-sky or even a maritime aerosol background (Torres et al., 2002). Highly absorbing carbonaceous and dust aerosols above the boundary layer are most sensitive to UV radiation. In general, $\mathrm{AI}$ is not sensitive to either aerosol types below the boundary layer top $(\mathrm{H}<\sim 2 \mathrm{~km})$. The relationship between UV radiation and absorbing aerosol concentration is defined in terms of the TOMS aerosol index (AI), which is the difference between the UV observations and model calculations from a pure molecular atmosphere with the same surface and 
atmospheric conditions. Positive AI values indicate the presence of UV-absorbing aerosols in the mid and upper troposphere, while near zero and negative values are indicative of non-absorbing, scattering, and/or, fine-mode aerosols near the surface.

For comparison purposes, data from the CALIOP instrument on the CALIPSO satellite are obtained for the 20062007 time frame, and seasonal averages of aerosol height for each region calculated. The CALIOP is an active lidar that provides vertical profiles of backscatter at 532 and $1064 \mathrm{~nm}$ that sample the vertical distribution of clouds and aerosols in the atmosphere (Vaughan et al., 2004). We use aerosollayer height retrievals from the CALISPO Level 2 ALAY5V2 product, which is still in its preliminary stages of validation. While uncertainties are high, these data do provide a quantitative assessment of aerosol height not available from the other instruments and are especially useful at examining differences in aerosol heights from region to region. We use the maximum aerosol layer height for our calculations; thus, resulting layer averages represent the maximum height to which aerosol are transported within any particular region. Thus, aerosols may (and likely do) exist below this layer as well. Since the dates of CALIPSO data availability do not overlap with the primary dataset used in this study, we assume that the 2006-2007 seasonal averages of AOT height for each region are consistent with previous years. The summer season consists of June, July, and August data (JJA) from 2006 and the winter season consists of data from December, January, and February (DJF) during 2006-2007.

\subsection{Meteorology}

Daily, global surface wind speed and direction, and relative humidity at 1000, 850 , and $700 \mathrm{hPa}$ levels are obtained from National Center for Environmental Prediction (NCEP) Reanalysis data. The NCEP Reanalysis contains global meteorological conditions with a 2.5 degree horizontal resolution and a 17 level vertical resolution $(1000-10 \mathrm{hPa})$ at $6 \mathrm{~h}$ time intervals (00:00, 06:00, 12:00, 18:00 UTC) (Kalnay et al., 1996). The reanalysis data set reliability captures synoptic scale dynamic and thermodynamic features, though often misses smaller scale phenomena. While all these parameters are compared to indirect effects to some extent, vertical velocity in particular is used to determine whether or not a certain region is favorable or unfavorable for cloud formation. NCEP data nearest in time to the satellite overpass time in each region are used. For example, if the overpass time is 14:00 UTC, satellite data are combined with NCEP data at 12:00 UTC.

\section{Methodology for calculating AIE}

All statistics such as correlations and regression coefficients between aerosol and cloud properties are computed using the CERES pixel-level data (with a daily temporal resolution and $\mathrm{a} \sim 20 \mathrm{~km}$ spatial resolution) within each $10 \times 10^{\circ}$ region for each month of data. Pixel-level data for each onemonth period are averaged to form monthly averaged values from which time-series of aerosol, cloud and atmospheric conditions are constructed. Anthropogenic and dust direct and indirect radiative effects are calculated using a modified form of the methods outlined by Quaas et al. (2008). As part of this process, the total AOT $(\tau)$ must be separated into its maritime (sea-salt), dust, and fine-mode constituents. For the purposes of this research, fine-mode aerosols are considered to be primarily anthropogenic in origin and are labeled as such. The Kaufman et al. (2005b, c) method is employed to calculate the portion of AOT resulting from each aerosol type (Jones and Christopher, 2007). This method assumes that maritime AOT is primarily a linear function of near surface wind-speed and that maritime $\left(\tau_{m a}\right)$, dust $\left(\tau_{d u}\right)$, and anthropogenic $\left(\tau_{a n}\right)$ aerosols each have characteristic FMF values that can be used as separation points between each aerosol type. The characteristic FMF values used here are the same as those employed by Jones and Christopher (2007), which do not vary as a function of region, but are allowed to vary as a function of time. The dust and anthropogenic components of AOT are derived by solving a series of mathematical relationships where maritime AOT is known, and one remaining unknown, $\tau_{d u}$ in this case, removed from the series of equations. The remaining component $\left(\tau_{d u}\right)$ is simply defined by subtracting $\tau_{a n}$ and $\tau_{m a}$ from observed AOT. Uncertainties in this method are explained in detail in Jones and Christopher $(2007,2008)$, where it is noted that the component AOT values have an uncertainty of between 30 and $50 \%$. Quaas et al. (2008) used the method outlined by Bellouin et al. (2005) to calculate the anthropogenic portion of the AOT. However, this method does not discriminate between sea-salt and dust aerosols, preventing the calculation of dust-only direct and indirect effects.

Dust direct radiative effect (DRE) and Direct Climate Forcing (DCF) due to anthropogenic aerosols are calculated using the incoming solar radiation derived from the satellite overpass time, solar zenith angle, and earth-sun distance, and then applying a diurnal adjustment factor $(D)$ (Bellouin et al., 2005; Jones and Christopher, 2007). Unlike Quaas et al. (2008), we apply the diurnal adjustment method used by Remer and Kaufman (2006) and the differences between these adjustments are small. The diurnally averaged DCF due to anthropogenic aerosols $\left(\Delta \mathrm{F}_{a}\right)$ can be expressed as the change in planetary albedo due to anthropogenic aerosols $\left(\Delta \alpha_{a}\right)$ multiplied by the incoming solar radiation at the top of the atmosphere $\left(\mathrm{F}_{s}\right)$ as shown in Eq. (2).

$\Delta F_{a}=\Delta \alpha_{a} F_{s}$

The change in planetary albedo due to anthropogenic aerosols is expressed by Eq. (3).

$\Delta \alpha_{a}=\frac{d \alpha}{d \ln (\tau)}\left[\ln (\tau)-\ln \left(\tau-\tau_{a n}\right)\right]$ 
Combining Eqs. (2) and (3) and using the empirical relationship derived for $\mathrm{d} \alpha / \mathrm{d} \ln (\tau)$, the anthropogenic DCF becomes

$\Delta F_{a}=-(1-f) a_{2}\left[\ln (\tau)-\ln \left(\tau-\tau_{a n}\right)\right] F_{s} D$

where $a_{2}$ is a constant defined by Quaas et al. (2008) and $f$ is the total cloud fraction. These and the following constants are computed as a function of season over several ocean domains and the appropriate values for each region are used. To calculate dust $\operatorname{DRE}\left(\Delta \mathrm{F}_{d}\right)$, the term $\ln \left(\tau-\tau_{a n}\right)$ is simply replaced by $\ln \left(\tau-\tau_{d u}\right)$ forming Eq. (5).

$\Delta F_{d}=-(1-f) a_{2}\left[\ln (\tau)-\ln \left(\tau-\tau_{d u}\right)\right] F_{s} D$

This research does not compute DRE using CERES shortwave radiance observations like previous research that use CERES-SSF data (e.g. Jones and Christopher, 2007). The primary reason is that we want to compare direct and indirect effects of aerosols in the same region, and using compatible methods greatly simplifies this process. Also, the method used here already takes into account the effect of cloud-cover eliminating the need for any sort of bias adjustment (Christopher and Jones, 2008).

The cloud albedo effect (or first indirect effect) is a function of the relationship between the number density of liquid water droplets in a cloud $\left(\mathrm{N}_{d}\right)$ and the AOT. Number density is not reported directly within the CERES-SSF product and must be calculated using cloud optical thickness $\left(\tau_{c}\right)$ and effective droplet radius $\left(r_{e}\right)$. Assuming adiabatic conditions, Brenguier et al. (2000) derive this relationship to be

$N_{d}=\gamma \tau_{c}^{1 / 2} r_{e}^{-5 / 2}$

where $\gamma=1.37 \times 10^{-5} \mathrm{~m}^{-0.5}$. The first anthropogenic indirect effect $\left(\Delta \mathrm{F}_{i a 1}\right)$ can be expressed by Eq. (7), where $\mathrm{A}\left(\mathrm{f}, \tau_{c}\right)$ is empirical function relating albedo to cloud fraction and cloud optical thickness. This function is explained in detail in the Appendix of Quaas et al. (2008).

$\Delta F_{i a 1}=-f A\left(f, \tau_{c}\right) \frac{1}{3} \frac{d \ln \left(N_{d}\right)}{d \ln (\tau)}\left[\ln (\tau)-\ln \left(\tau-\tau_{a n}\right)\right] F_{s} D$

When the correlation between $\mathrm{N}$ and $\tau$ is positive (e.g. more aerosols=more cloud droplets), the indirect effect becomes negative, cooling the atmosphere. If the correlation is negative, then $\Delta \mathrm{F}_{i a 1}$ becomes positive, opposite to the expected first indirect effect. To calculate the dust aerosol indirect effect $\left(\Delta \mathrm{F}_{\mathrm{id} 1}\right)$, the same substitution that is made for the direct effect (Eq. 4) is made to Eq. (7). The term $d \ln \left(\mathrm{N}_{d}\right) / d \ln (\tau)$ represents the linear regression fit between the natural logarithm of cloud droplet number density and AOT. This value is calculated on a month-by-month basis and is unique to each region studied. Uncertainties in this relationship are the greatest contributor to uncertainty in the reported in indirect effects using this method (Andreae, 2009).

Some clues about the second indirect effect, or cloud lifetime effect, were also described by Quaas et al. (2008). However, given the large uncertainties present in the relationship between cloud fraction, cloud liquid water path (LWP), and going from number density to AOT, we chose to primarily focus our results on the first AIE. The term "aerosol indirect effect" in the following discussion refers to the first AIE component only unless otherwise stated. We fully recognize that several uncertainties in both observations and cloud-aerosol interactions exist that complicate the interpretation of the resulting AIE values (in addition to the cloud contamination described above). Uncertainties in the aerosol classification process, which are described above, also result in an additional uncertainty for the dust vs. anthropogenic radiative effects. Based on known uncertainties, a 30\% difference between dust and anthropogenic effects must exist for it to be considered significant.

\section{Results}

\subsection{Regional direct and indirect effects}

A suite of general circulation models estimate that anthropogenic indirect effects range from -1.9 to $-0.3 \mathrm{Wm}^{-2}$ globally (Lohmann and Feichter, 2005; Forster et al., 2007). More recent observational studies indicate that the total anthropogenic AIE is likely on the lower side of this range, and possibly negligible in certain regions (Matsui et al., 2006; Quaas et al., 2008). No corresponding statistics for the indirect effects of dust aerosols are known to the authors. This research does not report globally averaged values, but instead focuses on regional differences in both the dust and anthropogenic indirect effects to determine under what conditions these effects are most likely to occur (Fig. 1). Table 1a,b lists dust and anthropogenic direct and indirect effects derived using the methods descried in Sect. 3 compared with cloud and aerosol properties derived from MODIS. Direct and indirect radiative effects reported here are diurnally averaged with no clear-sky bias adjustments necessary (Christopher and Jones, 2007; Quaas et al., 2008). AIE values are only reported where a statistically significant relationship between AOT and $R_{c}$ exists for a particular one-month period. Recall that Eq. (7) is highly dependent on the relationship between $\mathrm{AOT}$ and $\mathrm{N}$, where $\mathrm{N}$ is also a function of $R_{c}$. If this relationship is not significant, then any AIE values calculated using this equation would naturally be suspect. For the purposes of this work, statistically significant is defined as a $99 \%$ or greater confidence level using paired Student's T test. (Effective sample size is used to compute these statistics and represents approximately $50 \%$ of the original sample size due to auto and spatial correlation of the raw data). While the correlation between AOT and $R_{c}$ is expected to be negative when AIE is present, statistically significant positive correlations are not removed; thus, AIE "warming" is allowed to be included in the averages listed in Table $1 \mathrm{~b}$.

The largest aerosol direct effects are associated with the highest aerosol concentrations (Table 1a). The 6-year 
Table 1. Six year mean aerosol and cloud properties, and direct radiative effects for each region of study (a) Average dust and anthropogenic AIE for each region, with corresponding standard error values (b) Seasonally averaged of CTP (hPa) and total AIE (Wm ${ }^{-2}$ ) with seasonal averages (DJF and JJA, 2006-2007 only) of CALIPSO aerosol layer height (km), a.s.l. also listed.

\begin{tabular}{|c|c|c|c|c|c|c|c|c|c|c|}
\hline $\begin{array}{l}\text { a } \\
\text { Region }\end{array}$ & Code & AOT & $\tau_{a n}$ & $\tau_{d u}$ & $\mathrm{DRE}_{a n}$ & $\mathrm{DRE}_{d u}$ & COT & $\mathrm{CF}$ & $\mathrm{Rc}$ & CTP \\
\hline & & & & & {$\left[\mathrm{Wm}^{-2}\right]$} & {$\left[\mathrm{Wm}^{-2}\right]$} & & {$[\%]$} & {$[\mu \mathrm{m}]$} & {$[\mathrm{hPa}]$} \\
\hline Arabian Sea & AS & 0.33 & 0.16 & 0.11 & -3.0 & -1.0 & 1.9 & 57.8 & 14.2 & 852 \\
\hline Bay of Bengal & $\mathrm{BB}$ & 0.27 & 0.16 & 0.05 & -3.2 & -0.4 & 2.0 & 63.9 & 15.1 & 824 \\
\hline S. Indian Ocean & IO & 0.13 & 0.04 & 0.02 & -0.9 & -0.3 & 3.0 & 68.8 & 16.1 & 838 \\
\hline East North Atlantic & EA & 0.39 & 0.13 & 0.20 & -1.4 & -1.6 & 2.1 & 58.3 & 14.2 & 844 \\
\hline West North Atlantic & WA & 0.20 & 0.11 & 0.03 & -3.3 & -0.3 & 3.9 & 63.7 & 12.5 & 830 \\
\hline African Biomass & $\mathrm{AF}$ & 0.32 & 0.22 & 0.05 & -2.8 & -0.4 & 3.3 & 66.0 & 11.8 & 853 \\
\hline \multicolumn{11}{|l|}{ b } \\
\hline \multirow{2}{*}{ Region } & \multicolumn{2}{|c|}{ AIE } & \multicolumn{3}{|c|}{ DJF } & \multicolumn{3}{|c|}{ JJA } & & \\
\hline & $\begin{array}{l}\text { DUST } \\
{\left[\mathrm{Wm}^{-2}\right]}\end{array}$ & $\begin{array}{l}\text { ANTH } \\
{\left[\mathrm{Wm}^{-2}\right]}\end{array}$ & $\begin{array}{r}\mathrm{H} \\
{[\mathrm{km}]}\end{array}$ & $\begin{array}{r}\text { CTP } \\
{[\mathrm{hPa}]}\end{array}$ & $\begin{array}{r}\text { AIE } \\
{\left[\mathrm{Wm}^{-2}\right]}\end{array}$ & $\begin{array}{r}\mathrm{H} \\
{[\mathrm{km}]}\end{array}$ & $\begin{array}{r}\text { CTP } \\
{[\mathrm{hPa}]}\end{array}$ & $\begin{array}{r}\text { AIE } \\
{\left[\mathrm{Wm}^{-2}\right]}\end{array}$ & & \\
\hline AS & $-0.18 \pm 04$ & $-0.09 \pm 03$ & 1.5 & 864 & +0.10 & 3.3 & 801 & -0.78 & & \\
\hline BB & $-0.01 \pm .02$ & $+0.01 \pm 0.04$ & 1.4 & 833 & +0.06 & 2.5 & 755 & +0.22 & & \\
\hline IO & $-0.30 \pm 02$ & $-0.43 \pm 03$ & 1.1 & 823 & -0.54 & 1.2 & 829 & -0.64 & & \\
\hline EA & $+0.07 \pm 04$ & $+0.05 \pm 03$ & 1.9 & 812 & +0.33 & 3.3 & 830 & -0.43 & & \\
\hline WA & $-0.11 \pm 01$ & $-0.46 \pm 06$ & 1.3 & 819 & -0.48 & 1.4 & 805 & -0.89 & & \\
\hline $\mathrm{AF}$ & $-0.03 \pm 02$ & $-0.31 \pm 12$ & 2.8 & 812 & -0.01 & 3.1 & 871 & -0.45 & & \\
\hline
\end{tabular}

average of total column AOT is greater than 0.25 for regions AS, BB, EA, and AF. The combined dust and anthropogenic direct effects range between -3.0 and $-4.0 \mathrm{Wm}^{-2}$. However, corresponding AIEs do not necessary correspond to higher AOTs. The two regions with the lowest AOT: WA and $\mathrm{IO},(\tau=0.20,0.11$, respectively) both produce the two largest values for total $\operatorname{AIE}\left(-0.57,-0.73 \mathrm{Wm}^{-2}\right)$. In IO, the total (anthropogenic + dust) indirect effect of $-0.73 \mathrm{Wm}^{-2}$ is not that much less than the corresponding DRE value $\left(-1.2 \mathrm{Wm}^{-2}\right)$. Most of the AIE is from the anthropogenic component despite the lack of any nearby source of anthropogenic aerosols. However, approximately $50 \%$ of the total AOT is comprised of sea salt aerosols that are not accounted for in the direct and indirect calculations presented here and it is also possible fine mode aerosols such as DMS are being falsely classified as anthropogenic. While total AOT is also low in WA, fine mode primarily anthropogenic aerosols account for over $50 \%$ of the total AOT.

In regions where AOT is greater than 0.25, AIEs are observed under certain circumstances, but not others. In AS, a total AIE is $-0.27 \mathrm{Wm}^{-2}$, with over $60 \%$ being accounted for by the dust component, which may have a hygroscopic coating (Satheesh et al., 2006). If this is the case, then the largest AIE values would be expected when dust AOT is greatest so long as a significant anthropogenic aerosol background remains. In AF, average AOT is 0.32 , but the dust + anthropogenic direct radiative effect is only $-3.1 \mathrm{Wm}^{-2}$, somewhat less that expected for this aerosol concentration. However, this region contains the largest proportion of black carbon aerosols, which also absorb solar radiation and warm the atmosphere, which in turn reduces shortwave radiative efficiency while increasing atmospheric stability (Matsui et al., 2006). Here the anthropogenic AIE is $-0.31 \mathrm{Wm}^{-2}$ with the dust effect being only $-0.03 \mathrm{Wm}^{-2}$.

For BB and EA, both the dust and anthropogenic AIEs are small, indicating that other factors besides aerosols are significantly contributing to droplet growth, or lack thereof. In EA, the primary aerosol species is dust, which has usually not been thought of as good CCN (Levin et al., 1996). Unlike in AS, no significant concentration of anthropogenic aerosols exists to coat the dust and increase their solubility. $\mathrm{BB}$ is more of a mystery since sulfates account for a large proportion of the total AOT, with anthropogenic AOT and cloud property retrievals all being similar to those observed in AS. One key difference is that the concentration of elevated dust aerosols is much less in BB compared to AS (Table 1a, b). The physical mechanisms behind the differences in AIE from region to region are examined in detail in the following section.

Aerosol concentrations, direct and indirect effects all vary significantly as a function of cloud properties and atmospheric conditions resulting in a poor correlation between 
Table 2. Total AIE binned by thin $\left(\mathrm{LWP}<20 \mathrm{gm}^{-2}\right)$ vs. thick (LWP $\geq 20 \mathrm{gm}^{-2}$ ) clouds and $850 \mathrm{hPa}$ upward $\left(\omega<0 \mathrm{~Pa} \mathrm{~s}^{-1}\right)$ vs. downward $\left(\omega>\mathrm{Pa} \mathrm{s}^{-1}\right.$ ) vertical motion (a). Percentage of months (out of a possible 70) that a statistically significant relationships exists between AOT and $R_{c}$ (b). Sample size of each bin in terms of percent of total sample size (c). Percentage difference between the regression fit between AOT and $R_{C}$ over the range of AOT where the relationship is significant (d).

\begin{tabular}{|c|c|c|c|c|}
\hline $\begin{array}{l}\mathbf{a} \\
\text { Region }\end{array}$ & $(\mathrm{LWP}<20, \omega>0)$ & $(\mathrm{LWP}<20, \omega<0)$ & $(\mathrm{LWP}>20, \omega>0)$ & $(\mathrm{LWP}>20, \omega<0)$ \\
\hline AS & $-0.17 \pm .03$ & $-0.17 \pm .03$ & $-0.34 \pm .05$ & $-0.59 \pm .07$ \\
\hline $\mathrm{BB}$ & $-0.04 \pm .03$ & $-0.01 \pm .04$ & $+0.01 \pm .10$ & $-0.02 \pm .04$ \\
\hline IO & $-0.43 \pm .02$ & $-0.53 \pm .02$ & $-0.74 \pm .03$ & $-0.85 \pm .03$ \\
\hline EA & $+0.11 \pm .04$ & $+0.101 \pm .05$ & $+0.13 \pm .08$ & $+0.32 \pm .10$ \\
\hline WA & $-0.29 \pm .03$ & $-0.24 \pm .05$ & $-0.84 \pm .11$ & $-0.91+10$ \\
\hline $\mathrm{AF}$ & $-0.19 \pm .10$ & $-0.24 \pm .10$ & $-0.45 \pm .14$ & $-0.49 \pm 18$ \\
\hline \multicolumn{5}{|l|}{ b } \\
\hline AS & 81 & 71 & 70 & 50 \\
\hline $\mathrm{BB}$ & 60 & 50 & 43 & 51 \\
\hline IO & 74 & 66 & 100 & 100 \\
\hline EA & 81 & 70 & 70 & 71 \\
\hline WA & 57 & 33 & 57 & 61 \\
\hline $\mathrm{AF}$ & 59 & 46 & 77 & 60 \\
\hline \multicolumn{5}{|l|}{ c } \\
\hline AS & 60 & 19 & 8 & 13 \\
\hline $\mathrm{BB}$ & 51 & 20 & 15 & 14 \\
\hline IO & 12 & 8 & 44 & 36 \\
\hline EA & 42 & 27 & 17 & 13 \\
\hline WA & 29 & 13 & 29 & 30 \\
\hline $\mathrm{AF}$ & 33 & 15 & 36 & 17 \\
\hline \multicolumn{5}{|l|}{ d } \\
\hline AS & 39 & 41 & 44 & 46 \\
\hline $\mathrm{BB}$ & 28 & 37 & 31 & 23 \\
\hline IO & 31 & 31 & 21 & 21 \\
\hline EA & 31 & 33 & 33 & 28 \\
\hline WA & 24 & 33 & 33 & 28 \\
\hline $\mathrm{AF}$ & 22 & 29 & 28 & 28 \\
\hline
\end{tabular}

overall AOT and AIE (Jones and Christopher, 2008; Yuan et al., 2008). To assess the relative importance of aerosol concentrations and atmospheric conditions to cloud properties, AIE is examined as a function of thin ( $\mathrm{LWP}<20 \mathrm{gm}^{-2}$ ) vs. thick $\left(\mathrm{LWP} \geq 20 \mathrm{gm}^{-2}\right.$ ) clouds and whether or not corresponding $850 \mathrm{hPa}$ vertical motion is upward or downward (approximately representing conditions favorable and unfavorable for cloud formation and persistence). Recall that previous research has shown that AIE are more likely to occur in thicker clouds, often defined using LWP thresholds between 20 and $100 \mathrm{gm}^{-2}$ to separate thick from thin clouds (e.g. Lohmann et al., 2000; Lee et al., 2009). Similarly, thicker clouds should occur more often in the presence of upward motion; thus, AIEs should be greatest when both conditions are met. Table 2a lists total (anthropogenic + dust) AIE for each region averaged over a six-year period for months where a statistically significant relationship exists between AOT and $R_{c}$. The percentage of months where this rela- tionship is significant is also listed (Table 2b), with $100 \%$ indicating a statistically significant relationship exists for all 70 months of data analyzed. It should be noted that given the differences in samples sizes and distributions between each bin, an average of the four AIE values may not correspond exactly to the average (listed in Table 1b) calculated using the entire data set for a particular region.

In four of the six regions studied (AS, IO, WA, AF), AIE is greatest in the thick-cloud, upward motion sample though this is only marginally the case for AF. In region AS, AIE increases from a value of $-0.17 \mathrm{Wm}^{-2}$ for thin clouds occurring during subsidence to $-0.60 \mathrm{Wm}^{-2}$ for thicker clouds associated with upward motion. However, persistent upward motion associated with a thick cloud layer is only present $13 \%$ of the time compared to the other three possibilities with thin clouds accounting for nearly $80 \%$ of the data in this region. In WA and AF, the sample is evenly split between thin clouds and thick clouds with AIE in the thick cloud 

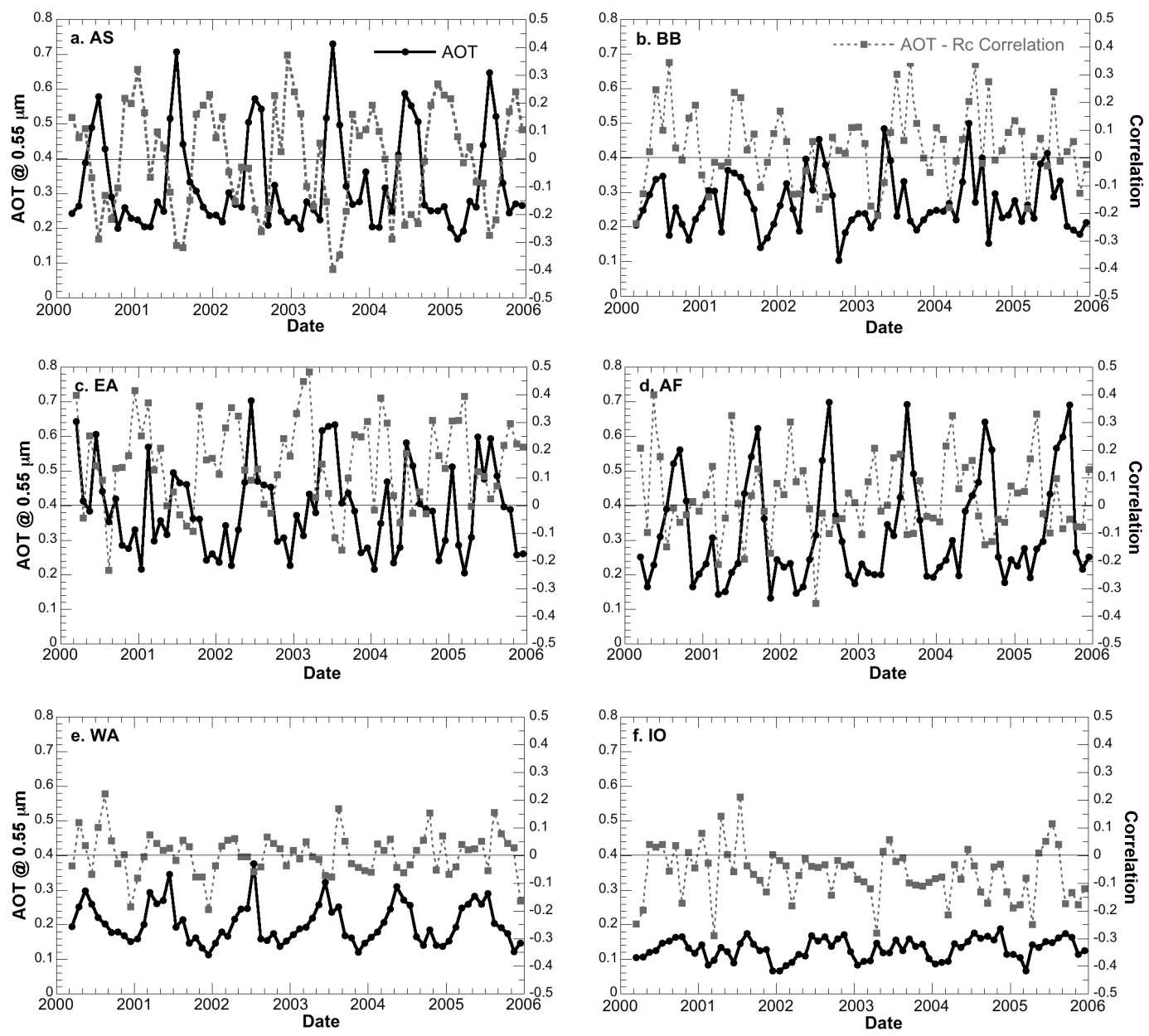

Fig. 3. Monthly mean MODIS total column AOT and correlation between AOT and $R_{C}$ for each region between 2000 and 2006 . Correlations in excess of \pm 0.1 are generally considered statistically significant. The time series of AOT $-R_{C}$ correlation is the gray line, and set to the right hand axis on each plot.

samples being $4 \times$ and $2 \times$ that of the thin cloud samples. For these two regions, the difference between thick clouds associated with upward motion vs. downward motion is generally smaller, being only $10-15 \%$. IO has the largest AIE values of the six regions studied, with thick maritime stratus clouds accounting for $80 \%$ of the sample. As before, AIE is greatest where thick clouds and upward motion are present. The difference in AIEs is generally greater between thick clouds vs. thin clouds compared to rising vs. sinking motion, but upward motion combined with thicker clouds did increase AIE compared to thick clouds associated with downward (or little) vertical motion for each of these four regions providing evidence that atmospheric conditions must be considered when estimating AIE. In fact, part of this increase may be due to adiabatic cooling associated with rising parcels of air in already humid environments. This cooling increases $\mathrm{RH}$, further promoting the formation of clouds, while also increasing the possibility of humidified aerosols as well. For most regions, relative humidity was indeed greatest for the thick cloud, upward motion sample. However, when comparing AIE against solely RH, no significant relationships could be found. If adiabatic cooling was the dominant source for AIE, then the relationship between AIE and RH should be more apparent; thus, we do not believe that the increase in AIE for this sample is primarily due to this effect. While the 6year averages indicate that AIE are indeed greatest for thick clouds in the presence of upward motion in regions AS, IO, $\mathrm{WA}$, and AF, indirect effects also existed for the other cases. What this means is that indirect effects can still occur under less than ideal conditions, but that the magnitude of the effects will generally be less.

Regions BB and EA appear to behave differently than the four regions described above.

In BB, AIE is approximately $0 \mathrm{Wm}^{-2}$ for all four sets of cloud and atmospheric conditions (Table 2a). With the exception of dust aerosols, cloud and aerosol properties are similar to those present in AS. The lack of AIE in the BB may be due to differences in the vertical velocity profiles, 

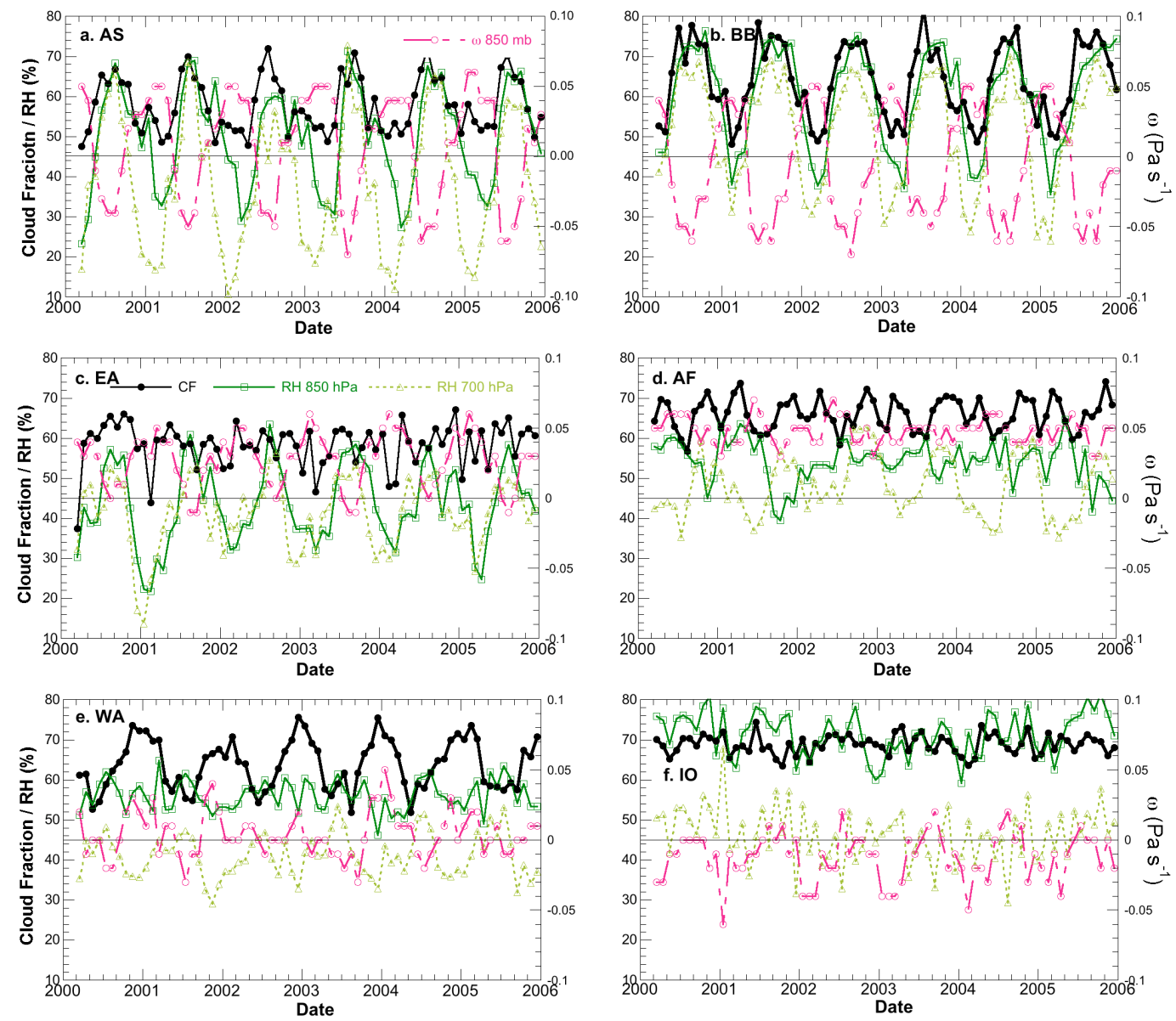

Fig. 4. Monthly averaged NCEP 850 and $700 \mathrm{hPa}$ relative humidity (\%), $850 \mathrm{hPa}$ vertical velocity (Pa s${ }^{-1}$ ), and MODIS cloud fraction for each region. Upward motion is indicated by negative values.

humidity, and relative positions of the cloud and aerosols layers. These possibilities are explored in detail below in the following section. In EA, AIE values are weakly positive in all cases, opposite that expected. Even more interesting is that the warming is greatest for thick clouds associated with rising motion $\left(+0.32 \mathrm{Wm}^{-2}\right)$. In EA, it has been surmised that the semi-direct effect (warming from absorbing aerosols), outweighs the importance of the microphysical aerosol - cloud relationship normally expected for AIEs. This warming can lead to subsidence and/or increased cloud evaporation, reducing cloud cover and possibly AIE.

To determine if the estimates of AIE are indeed significant and not just a result uncertainties AOT retrievals near clouds, we use the magnitude of the change in effective cloud radius as a function of AOT as a guide. For each of the four cloud-type, vertical motion samples created above, if the linear regression fit between AOT and $R_{C}$ is statistically significant (and negative), and the fitted $R_{c}$ varies more than $15 \%$ between the minimum and maximum observed AOT, then at least a portion of the relative changes between aerosol and cloud properties is deemed to be a result of aerosols, and not artifacts. This difference threshold is based on the difference in FMF observed as a function of cloud fraction for each region shown in Fig. 2c and discussed in Sect. 3. The largest differences $(\sim 40 \%)$ occur in AS, and are maximized for the upward motion, thick cloud sample; thus, we are quite confident that the results from this region are not due to observational artifacts. Most other regions and samples have differences of $\sim 30 \%$, which also exceeds our predefined threshold by a factor of 2 . While the differences in AOT and $R_{c}$ are considered physically meaningful using the tests applied here, they do not necessarily indicate that large AIE are occurring.

There exist several limitations with this test. Two regions in particular are of interest, EA and IO. Recall that FMF changed little as a function of cloud fraction in EA due to the presence of primarily non-hygroscopic aerosols. Since we assume that the change in FMF as a function of cloud fraction is primarily due to the increase in aerosol size due to hygroscopicity, then any AOT $-R_{c}$ relationship in EA would 

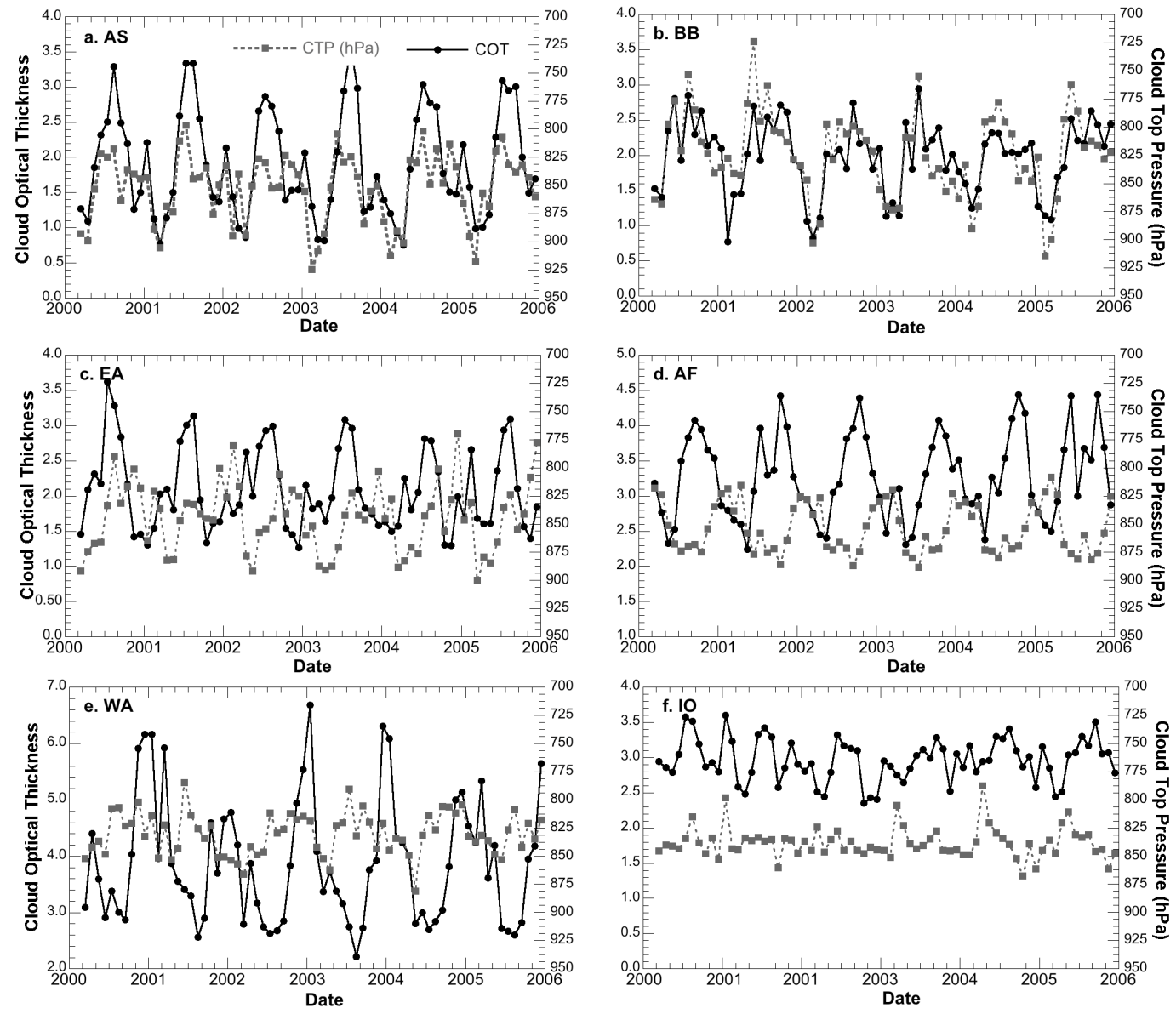

Fig. 5. Monthly averaged cloud optical thickness (COT) and cloud top pressure (CTP, hPa) for each region.

be considered significant. In IO, FMF actually increases with cloud fraction, completely opposite that expected by the FMF test. However, the aerosol - cloud interactions in these two regions are substantially different from those in the other four regions and the details of which are described below.

\subsection{Seasonal variation in AIE}

\subsubsection{Arabian Sea (AS)}

Aerosol indirect effects vary substantially as a function of time in all regions; thus, it is important to analyze aerosol, cloud, and atmospheric conditions as a function of time to assess the specific physical processes occurring. In the AS, the maxima in cloud fraction and COT during JJA correspond well with maxima in $850,700 \mathrm{hPa}$ humidity and $850 \mathrm{hPa}$ vertical velocity (Figs. 3-6a). In fact, most of the thick-cloud, upward motion sample shown in Table 2a occurs during JJA, with very few points present outside the summer months. AOT is also maximized at the same time, primarily from an influx of elevated dust aerosols and increased production of sea salt due to higher wind speeds. Correlation between $R_{c}$ and AOT is indeed most negative in JJA with a correlation coefficient of -0.3 averaged over JJA for all years. Similar results were observed by Patra et al. (2007), also indicating maximum indirect effects during the summer months. The cloud droplet effective radius is also greatest during the summer months, when moisture and cloud thicknesses are greatest. This differs from the finding by Chylek et al. (2006) who observed smaller droplet radii in September (high AOT) compared to larger radii in January (low AOT). However, their spatial domain was substantially larger than used here; thus, their statistics are not necessary valid for the smaller Arabian Sea domain used by this research.

Both anthropogenic and dust AIEs are maximized in the summer, with values near $-1.0 \mathrm{Wm}^{-2}$, consistent with expectations (Fig. 6a). Based on the magnitude of the change in $R_{c}$ relative to AOT ( $>40 \%$ ), these estimates of AIE are considered a reflection of process outlined by Twomey (1977) and many others. The difference in AIE values between summer and winter estimates is also significant. In the winter, the correlation between $R_{c}$ and AOT is weak resulting in both anthropogenic and dust AIE being small, despite the 

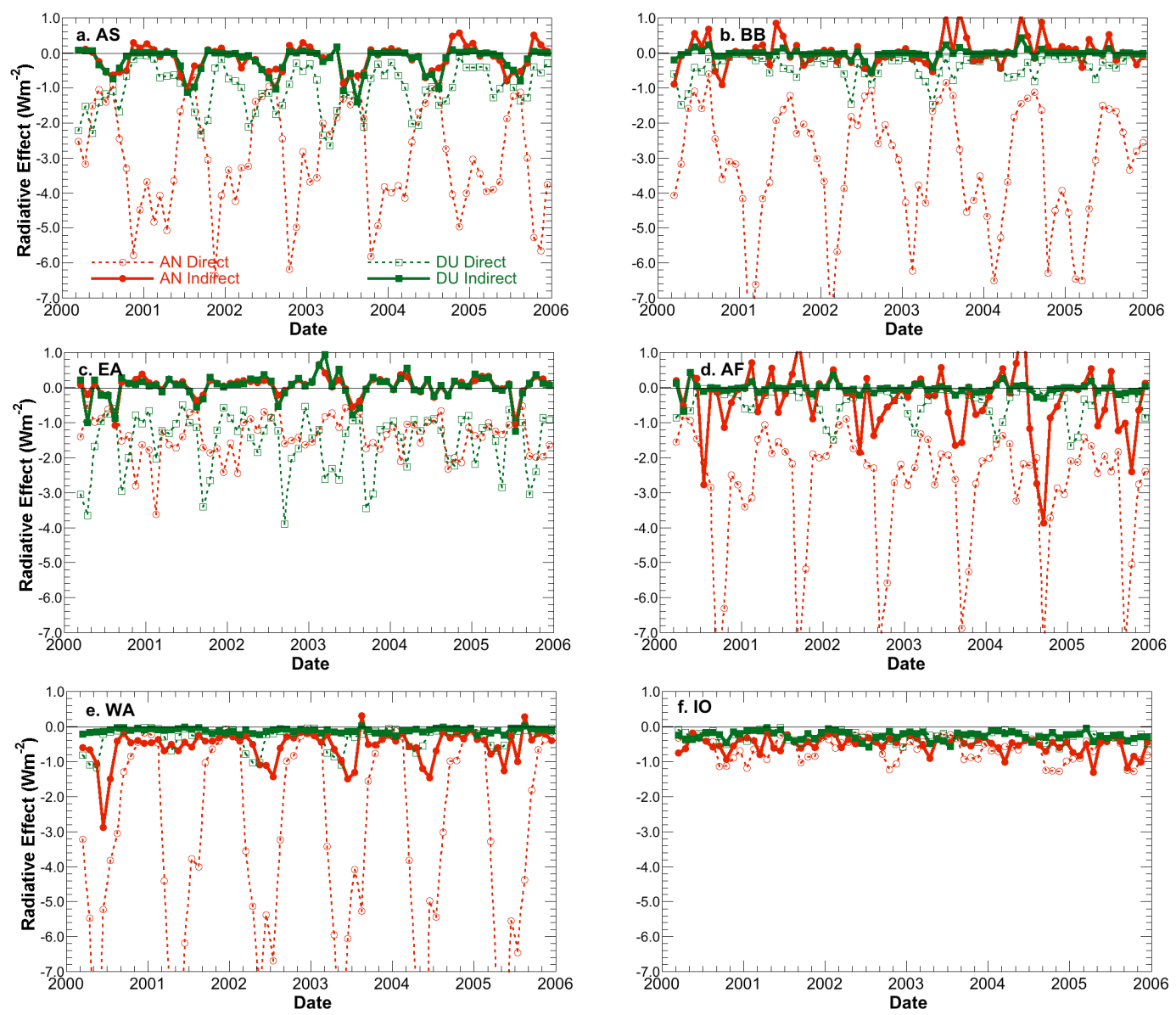

Fig. 6. Monthly averaged direct and indirect dust (DU) and anthropogenic (AN) aerosol effects. Note the seasonal variability of direct radiative effects in all regions, which is consistent with the seasonal variability of total AOT in Fig. 3. Indirect effects only show seasonal cycles for certain regions, and are generally smaller that direct radiative effects.
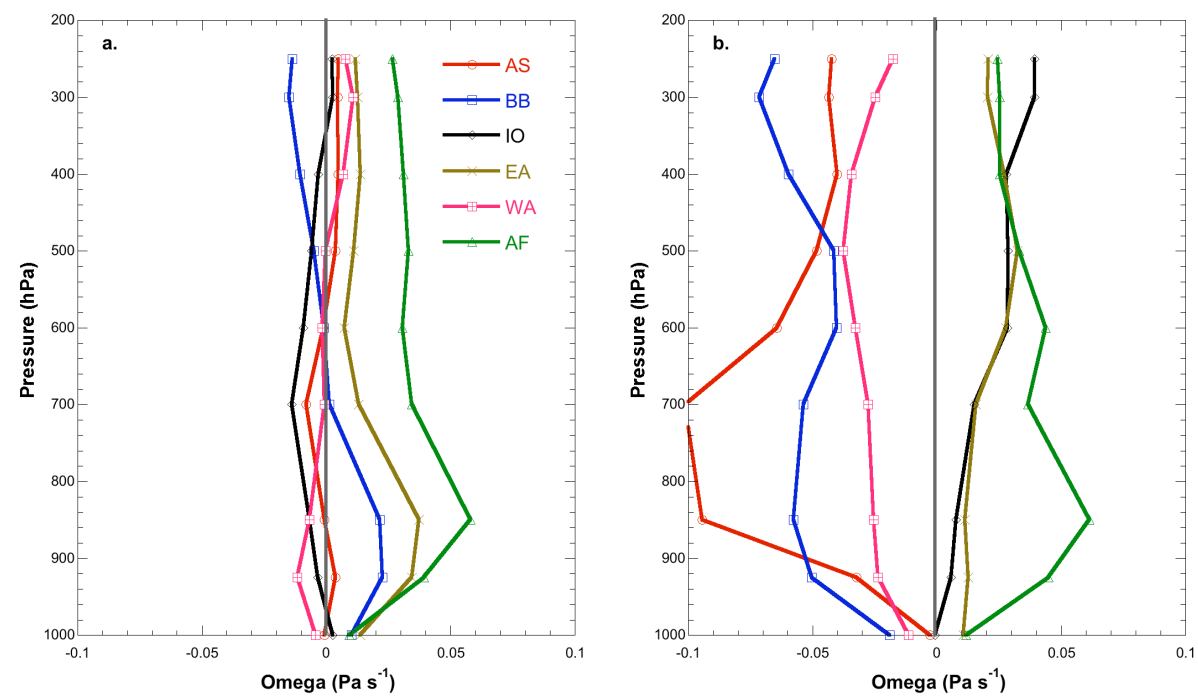

Fig. 7. Seasonally averaged (a DJF, b JJA) vertical velocity acquired from NCEP reanalysis data between 1000 and 250 hPa at 12:00 UTC for each region. Upward motion is indicated by negative values, with gray lines indicating zero vertical motion. 


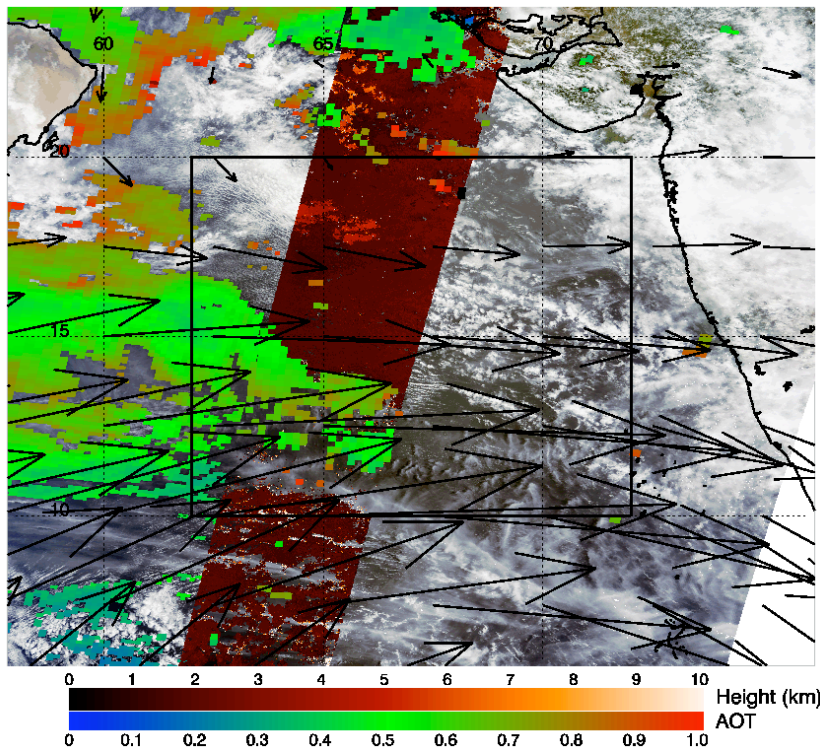

Fig. 8. Terra MODIS three band overlay for 8 August 2003 with AOT at $0.55 \mu \mathrm{m}$ from both MODIS and MISR overlaid. The MISR stereo height product represents the height above sea level the upper most cloud layer is located. Vectors indicate $850 \mathrm{hPa}$ wind speed and direction.

monthly averaged $R_{c}$ also being small compared to the overall mean value (11.0 vs. $14.2 \mu \mathrm{m})$. Here, atmospheric humidity is less and vertical motion is weak, inhibiting cloud formation leaving relatively thin clouds as evidenced by the decrease in COT (Figs. 5a, 7a). Comparison of thin $\left(\mathrm{LWP}<20 \mathrm{gm}^{-2}\right)$ vs. thick $\left(\mathrm{LWP}>20 \mathrm{gm}^{-2}\right.$ ) clouds shows that total AIE associated with the thick cloud sample is nearly double that associated with the thin cloud sample (Table 2a). While total AOT is greatest during the summer months, anthropogenic DRE is maximized during November and December when the anthropogenic portion of the AOT is greatest with values exceeding $-5.0 \mathrm{Wm}^{-2}$ (Fig. 6a).

The question remains as to whether or not the dust AIE reported here is actually from pure dust aerosols only. It is possible that that some maritime sea salt aerosols are being classified as dust by the algorithm. Dust coated with sulfates may also be part of the dust component (Levin et al., 1996; Seinfeld and Pandis, 1998); thus, causing "dust" AIE to appear larger than AIE from the fine mode component of aerosol alone. Between June and August (JJA), sustained upward vertical motion from near the surface up to at least $600 \mathrm{hPa}$ may be aiding both by transporting anthropogenic aerosols high enough into the atmosphere to interact with some of the dust aerosols present (Fig. 7b). Since AIE values for both dust and anthropogenic aerosols are similar and given the uncertainties inherent in the aerosol classification process, we cannot unambiguously determine which is most important in this region. However, the results strongly indicate that both aerosol types, possibility mixing with each other, are important to AIE in this region.

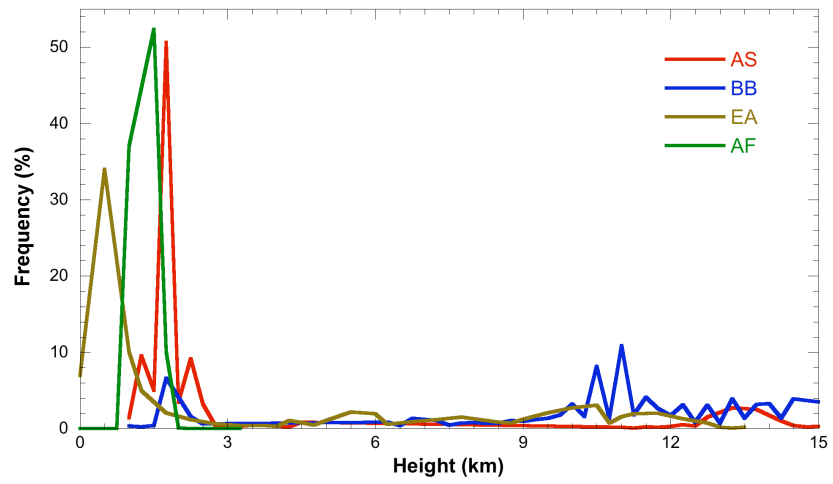

Fig. 9. Frequency histograms of MISR stereo height $(\mathrm{km})$ for each selected example. All regions except BB have a large peak below $3 \mathrm{~km}$, whereas BB indicates a greater proportion of clouds above $10 \mathrm{~km}$.

Finally, it is important to determine whether or not the elevated dust aerosols are co-located with cloud heights. To examine this last question, we compare the seasonally averaged cloud top pressures derived above with CALIPSO aerosol layer heights for winter (DJF) and summer (JJA) time periods. In this region, aerosol layer height increases from $1.6 \mathrm{~km}$ in DJF to $3.3 \mathrm{~km}$ in JJA, primarily corresponding to the influx of dust aerosols (Table 1b). For the same time periods, CTP is 864 and $805 \mathrm{hPa}$ or approximately 1.3 and $2.1 \mathrm{~km}$ above the ocean surface. These layers are somewhat below the maximum aerosol height layers from CALIPSO; however, the aerosol layer averages only represent a maximum ceiling to the aerosols. As such, they are also likely to exist below this height as well. Since these thicker clouds occur within a deep layer of aerosols, some of which are hygroscopic by nature or coating, AIE should be most significant during this period and the seasonally averaged total AIE agrees with this hypothesis (+0.10 vs. $-0.78 \mathrm{Wm}^{-2}$, Table 1b).

We further examine the importance of aerosol height vs. cloud height using from the MISR Stereo height product that are analyzed for 8 August 2003 corresponding to the time period when AIE in the Arabian Sea is maximized. MISR estimates of cloud heights in the Arabian Sea generally range between 1 and $3 \mathrm{~km}$ a.s.1., while significant aerosol concentrations are also evident from overlaid MODIS AOT data (Figs. 8, 9). While aerosol heights are not directly sampled, the average TOMS-AI values for this day (1.8) indicate the presence of elevated dust aerosols well above $1 \mathrm{~km}$ a.s.l. Vertical velocity $(\omega)$ at $15^{\circ} \mathrm{N}$ and $67.5^{\circ} \mathrm{W}$ shows that upward motion is maximized between 850 and $700 \mathrm{hPa}$, with $\omega$ remaining negative up to $400 \mathrm{hPa}$ (Fig. 10). Since both aerosols and clouds exist in the same atmospheric column where upward motion favorable for cloud formation is present, AIEs are quite likely to occur. Evidence for this is observed in correlation between AOT and $R_{c}$ for this day, 


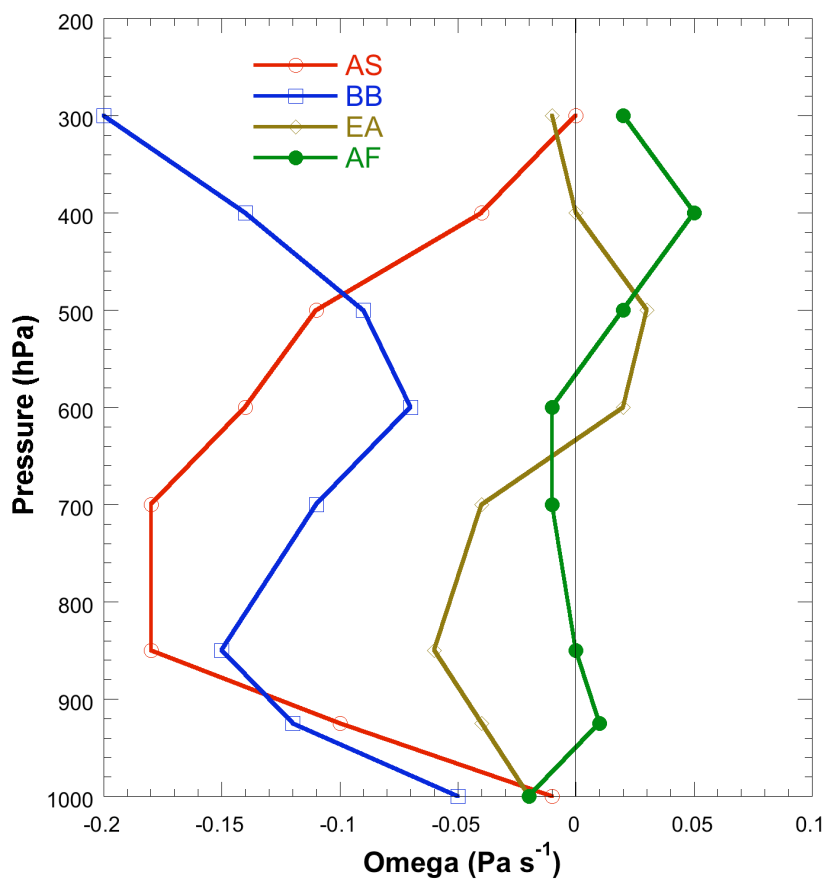

Fig. 10. Same as Fig. 7, but vertical velocities corresponding to date and time of the MODIS-MISR examples for regions AS, BB, EA, and $\mathrm{AF}$,respectively. Note that upward motion below the freezing level is generally greatest in AS.

which is -0.35 . Overall, comparisons of aerosol and cloud properties within this region support the hypothesis the AIE is more likely to occur where upward vertical motion and thicker clouds are present.

\subsubsection{Bay of Bengal (BB)}

In the Bay of Bengal, a similar pattern exists as in the Arabian Sea. AOT is maximized in the summer due to increase dust aerosol transport and some increase in sea-salt production. The magnitude of this increase is much smaller than that observed in AS ( $\tau_{d u}=0.05$ vs. 0.11 ), and fine mode aerosols account for larger proportion of the total AOT. Comparisons of model and observed aerosol speciation by Jones and Christopher (2007) suggest that the fine mode aerosols consist primarily of sulfates. The mean anthropogenic AOT component is nearly identical for both regions $\left(\tau_{a n}=0.16\right)$. As in the Arabian Sea, anthropogenic DRE is maximized during the winter with values between -6 and $-8 \mathrm{Wm}^{-2}$ (Fig. 6b). The corresponding increase in summertime dust DRE is much smaller $\left(-1.0 \mathrm{Wm}^{-2}\right)$. Cloud fraction, cloud droplet effective radius, AOT, relative humidity, and upward vertical velocity are all again maximized in the summer. Unlike the Arabian Sea, no corresponding increase in the either anthropogenic or dust AIE is readily apparent (Figs. 3b, 6b). Binning data relative to thick vs. thin clouds, or upward vs. downward $850 \mathrm{hPa}$ vertical motion did not produce a sample where significant AIE is present (Table $2 \mathrm{a}$ ).

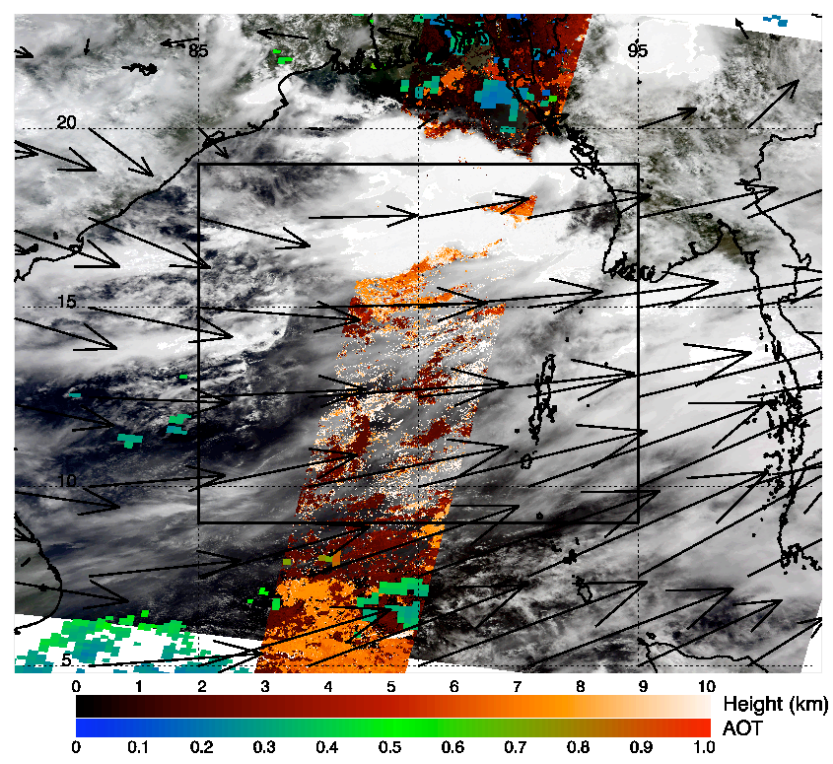

Fig. 11. Terra MODIS three band overlay for the Bay of Bengal on 23 July 2003, but otherwise similar to Fig. 8. Note the greater amounts of cirrus compared to low level stratus in this example compared to other regions.

Why AIE is not being observed is an important question with many possible answers. The magnitude correlation between AOT and $R_{c}$ is generally smaller and is only statistically significant for $\sim 50 \%$ of the months studied when thick clouds are present, during which AIE is expected to be greatest (Table 2b). Even when significant, the magnitude of these correlations is smaller, resulting in lower values of AIE. Several possible reasons exists for this weak correlation. First, total AOT in BB is less than that observed in AS, even though the difference is primary due to the lack of dust aerosols. Differences in the vertical velocity characteristics are also present. During the summer months, upward vertical motion in the Bay of Bengal between 850 and $700 \mathrm{hPa}$ is only half that observed in the Arabian Sea. Conversely, upward motion above $400 \mathrm{hPa}$ is slightly greater. Thus, favorability for warm-cloud formation below $5 \mathrm{~km}$ is not as great. Another significant difference in Arabian Sea vs. Bay of Bengal conditions is the relative heights of the aerosol and cloud layers between both regions. On average, cloud top pressures are approximately $30 \mathrm{hPa}$ higher than in the Arabian Sea with this difference increasing to $50 \mathrm{hPa}$ in JJA, but the aerosols themselves are present lower in the atmosphere. During DJF, average CALIPSO aerosol layer height for this region is $1.4 \mathrm{~km}$, similar to AS for which the layer height is $1.5 \mathrm{~km}$ (Table $1 \mathrm{~b}$ ). However, during JJA, aerosol layer height only increases to $2.5 \mathrm{~km}$ due to the lack of elevated dust aerosols and the weaker upward motion present preventing the transport of near-surface aerosols higher into the atmosphere. Conversely, CTP pressure is higher in BB compared to AS for JJA, which indicates a possible disconnect 
between cloud and aerosol layer properties, limiting AIE (Table $1 \mathrm{~b}$ ). If the clouds were thicker (i.e. extending from near the surface to the $800 \mathrm{hPa}$ layer), COT should be higher than observed in AS. This is not the case as both had averaged values of near 2 (Table 1a); thus, cloud bases in BB must also be higher. Unfortunately given the data available, we cannot further quantify the relative importance of these differences, but only state that these represent possible reasons that are consistent with expectations and previous research.

However, we can analyze the situation in more detail through a case study. In the Bay of Bengal, at least two cloud layers are present in an example from 23 July 2003 (Fig. 11). The most predominate cloud type appears to be cirrus clouds resulting from small pockets of convective activity with heights above $10 \mathrm{~km}$ a.s.l. Below this layer exist a few maritime status and cumulus clouds, but their overall areal coverage is low. The distribution of MISR stereo heights within this region exhibits a distinct bi-model distribution, with maxima at 2 and 10-11 km (Fig. 9). NCEP data at $15^{\circ} \mathrm{N}$ and $90^{\circ} \mathrm{W}$ also shows a bi-modal distribution of vertical velocity with two levels where upward motion is maximized, 850 and $300 \mathrm{hPa}$ (Fig. 10). Relative humidity is also high $(86 \%)$ at this level indicating the presence of this second cloud layer. Mean TOMS-AI is much lower (0.4) than in the Arabian Sea, which is due to a lower elevated dust aerosol concentration. As previously noted, aerosols in the Bay of Bengal are generally anthropogenic in nature with the greatest concentration likely present with the maritime boundary later $(<1.5 \mathrm{~km})$. Most of the clouds in this example appear to be located above the aerosol layer limiting the probably, or at a minimum, the observability of the indirect effect on liquid water clouds. These observations are consistent with the long term time-series analyzed above, and provide further evidence that cloud formation at least in this case is less favored in the Bay of Bengal.

\subsubsection{Eastern North Atlantic (EA)}

In the eastern North Atlantic, aerosols primarily originate from dust over the Saharan Desert and are advected westward by the prevailing winds (Dunion and Veldon, 2004; Kaufman et al., 2005b). Elevated dust aerosol concentration is maximized in the late spring and summer months, leading to a seasonal cycle in AOT and dust DRE (Figs. 3-6c). CALIPSO data for JJA 2006 indicated that these aerosols are located between 3 and $4 \mathrm{~km}$ above the ocean surface (Table 1b). Cloud fraction remains approximately constant at $60 \%$ with the exception of decreases occurring during the months of December and January (Fig. 4c). While cloud fraction does not change substantially, COT does increase during the summer months in association with the northward movement of the ITCZ. During this time, atmospheric moisture is maximized and overall vertical velocities are near zero. (Upward vertical motion is present within the individual convective elements along the ITCZ, but the poor resolution of the NCEP data washes out much of smaller scale upward motion actually present.) By contrast, very low humidity $(<30 \%)$ exists during the winter months when strong subsidence also present.

There does exist a seasonal cycle in the relationship between AOT and $R_{c}$, with a statistically significant positive correlation present during the winter months, where AOT and moisture content are lower (Fig. 5c). In the summer the correlation is often near zero. This cycle is consistent with that observed in the Arabian Sea, with the exception that the AOT $-R_{c}$ correlation never quite becomes consistently negative. The overall dust and anthropogenic AIEs are small $\left(+0.03\right.$ and $\left.+0.05 \mathrm{Wm}^{-2}\right)$ and mostly positive, indicating a slight warming effect. Interestingly, AIE is most positive for the thick-cloud, upward motion sample with a value of $+0.32 \mathrm{Wm}^{-2}$ even though it is here where the greatest cooling would generally be expected (Table 2a). Negative AIE values due to dust and anthropogenic aerosols are only observed in JJA, and the average JJA value reported $\left(-0.43 \mathrm{Wm}^{-2}\right)$ is skewed negative somewhat by three months where total AIE exceeds $-1.0 \mathrm{Wm}^{-2}$.

One possible reason for AIE not being larger on a consistent basis is the mid-level dry air and increased stability associated with large dust outbreaks (Dunion and Veldon, 2004). Depending upon their properties, dust aerosols absorb solar radiation, thereby warming mid-levels of atmosphere (700-500 hPa) leading to stabilization, suppressing convection and cloud formation, also known as the semi-direct effect (Ackerman et al., 2000; Koren et al., 2008; Matsui et al., 2006). Over $85 \%$ of the sample consists of either thin clouds, or thick clouds associated with downward motion, which is consistent with conditions being unfavorable. However, a similar sample distribution is present in AS, where cooling due to AIE is present. This hypothesis alone would also not explain why AIE is most positive for the thick cloud, upward motion sample. Another possibility is that the $850 \mathrm{hPa}$ upward motion transports dust aerosols higher into the atmosphere, increasing the magnitude of the semi-direct effects relative to AIE. However, give the coarse resolution of the atmospheric data used here, it is difficult to say for sure if either of these phenomena is occurring. Finally, it is possible that the dust aerosols, which are non-hydroscopic anyway, exist too high in the atmosphere to have significant microphysical interactions with lower-level clouds. From CALIPSO data, dust aerosols where located between 3 and $4 \mathrm{~km}$ in JJA, whereas the cloud tops from this study averaged only $1.6 \mathrm{~km}$ a.s.l. Also, the lack of a significant anthropogenic component to the total AOT in EA means that the potential for the dust aerosols to obtain a hygroscopic coating is much smaller. Thus, the combined lack of large scale ascent, nonhygroscopicity of aerosols, and co-location of aerosol and clouds layers all combine to limit AIE in this region even though AOT itself is high ( $\tau 0.39)$. 
Table 3. MODIS AOT and CTP, TOMS-AI, MISR Stereo heights, NCEP vertical velocity at $\left.850 \mathrm{hPa}^{(\mathrm{Pa} \mathrm{s}}{ }^{-1}\right)$, and derived dust and anthropogenic AIE $\left(\mathrm{Wm}^{-2}\right)$ for the days corresponding to the examples shown in Figs. 7, 9-11.

\begin{tabular}{lrlrrrrrr}
\hline Region & Date & AOT & AI & $\begin{array}{r}\mathrm{CTP} \\
{[\mathrm{hPa}]}\end{array}$ & $\begin{array}{r}\text { MISR } \\
{[\mathrm{km}]}\end{array}$ & $\begin{array}{r}\omega 850 \\
{\left[\mathrm{~Pa} \mathrm{~s}^{-1}\right]}\end{array}$ & $\begin{array}{r}\mathrm{IE}_{d u} \\
{\left[\mathrm{Wm}^{-2}\right]}\end{array}$ & $\begin{array}{r}\mathrm{IE}_{a n} \\
{\left[\mathrm{Wm}^{-2}\right]}\end{array}$ \\
\hline AS & 8 Aug 2003 & 0.58 & 1.8 & 800 & 3.6 & -0.18 & -2.1 & -0.1 \\
BB & 23 Jul 2003 & 0.22 & 0.4 & 721 & 10.7 & -0.13 & 0.9 & 0.4 \\
EA & 23 Jul 2004 & 0.59 & 1.8 & 816 & 3.9 & -0.06 & -0.4 & -0.4 \\
$\mathrm{AF}$ & 30 Sept 2004 & 0.61 & 1.5 & 860 & 1.5 & 0 & 0 & -3.3 \\
\hline
\end{tabular}

MODIS/MISR observations on 23 July 2004 show large dust aerosol concentrations west of the African coast (Fig. 12). Convective clouds extending up to $10 \mathrm{~km}$ a.s.l. according to MISR stereo height retrievals are present south of an $850 \mathrm{hPa}$ low pressure center $\left(-25^{\circ} \mathrm{W}, 14^{\circ} \mathrm{N}\right)$. However, the average cloud top pressure for liquid water clouds during this month is $842 \mathrm{hPa}$. Dust aerosols that may be above the freezing level $(\sim 550 \mathrm{hPa})$ may act also as ice condensation nuclei (DeMott et al., 2003). This effect, however, is outside the scope of this research. Significant dust aerosol concentrations are present with total AOT being 0.59 with a corresponding TOMS-AI of 1.8. However, total AIE is only $-0.8 \mathrm{Wm}^{-2}$. As with the overall monthly mean, vertical motion is weak during this day, with even some subsidence being observed as low as $700 \mathrm{hPa}$. This example does at least contain weak upward motion and a weak AIE compared to the neither in the long term sample, but with an AOT of 0.59, much greater AIE values would be expected if more of the aerosols were hygroscopic and non-absorbing.

\subsubsection{Eastern South Atlantic (AF)}

In the eastern South Atlantic off the African coast, aerosols primarily originate from biomass burning producing of large amounts of carbon based aerosols, especially between August and October (e.g. Lindesay et al., 1996). These aerosols are transported westward from central and southern Africa, leading to high AOT values $(>0.6)$ with a mean aerosol layer height of approximately $3 \mathrm{~km}$ throughout the year (Table 1b). These aerosols produce an anthropogenic DCF of $-8.0 \mathrm{Wm}^{-2}$ in August and/or September, which is very consistent year over year (Fig. 6d). A secondary maximum in dust aerosol concentration and DRE is present during February and March, with maximum values of $-2.0 \mathrm{Wm}^{-2}$. With the exception of $2001,850 \mathrm{hPa}$ atmospheric humidity and vertical velocity (consistent subsidence at all levels) do not change substantially as a function of time with over $70 \%$ of the sample consisting conditions where subsistence is present (Table 2c). Anthropogenic AIE is only present during these months for all years except 2001 and is greatest in the presence of the thicker clouds $\left(-0.45 \mathrm{Wm}^{-2}\right)$ with the upward motion sample only being slightly greater than the downward

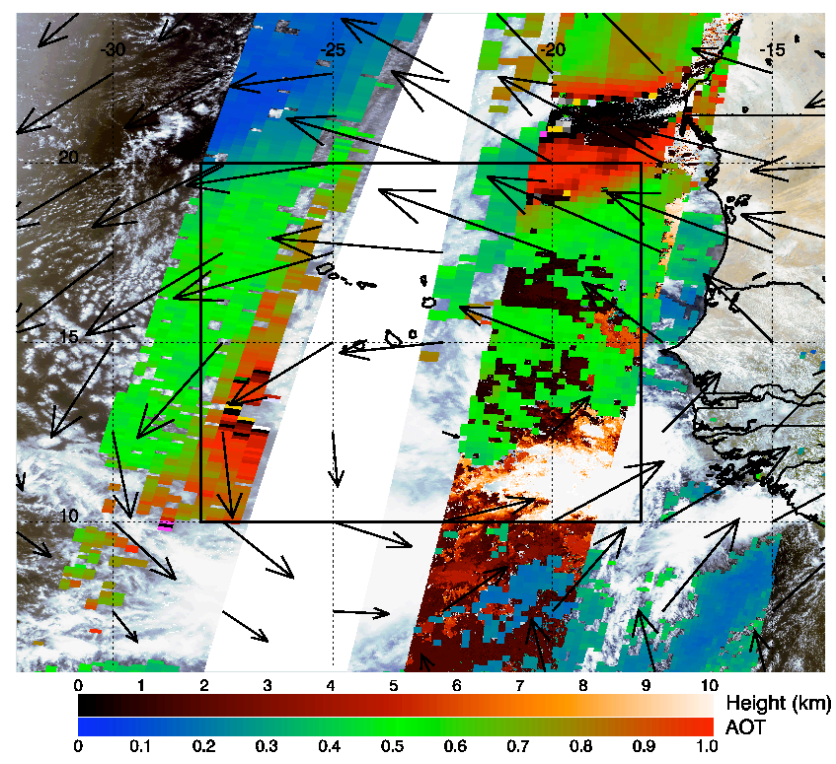

Fig. 12. Terra MODIS three band overlay for the North Eastern Atlantic (EA) region on 23 July 2004.

motion sample (Table 2a). For the six-year period of study, the dust + anthropogenic AIE is only $-0.4 \mathrm{Wm}^{-2}$, but this value is almost entirely due to the negative anthropogenic values observed during the August - October biomass burning season, which are on the order of $-3.0 \mathrm{Wm}^{-2}$ (Fig. 6d). Otherwise, both dust and anthropogenic AIEs are negligible. AF differs from other regions such as AS and IO in that large AIEs are not necessarily maximized when upward vertical motion at $850 \mathrm{hPa}$ is present, though the differences between thin vs. thick clouds remains clearly evident. In fact, the only other favorable atmospheric condition after August is the increase in $700 \mathrm{hPa}$ humidity, which is the level associated with the primary aerosol layer. However, monthly mean CTP is only $853 \mathrm{hPa}$, and is even greater during the summer and fall. Thus either the biomass burning aerosols are well mixed between the surface and $3 \mathrm{~km}$ level, or the relatively few deep clouds are responsible for the majority of AIE. 


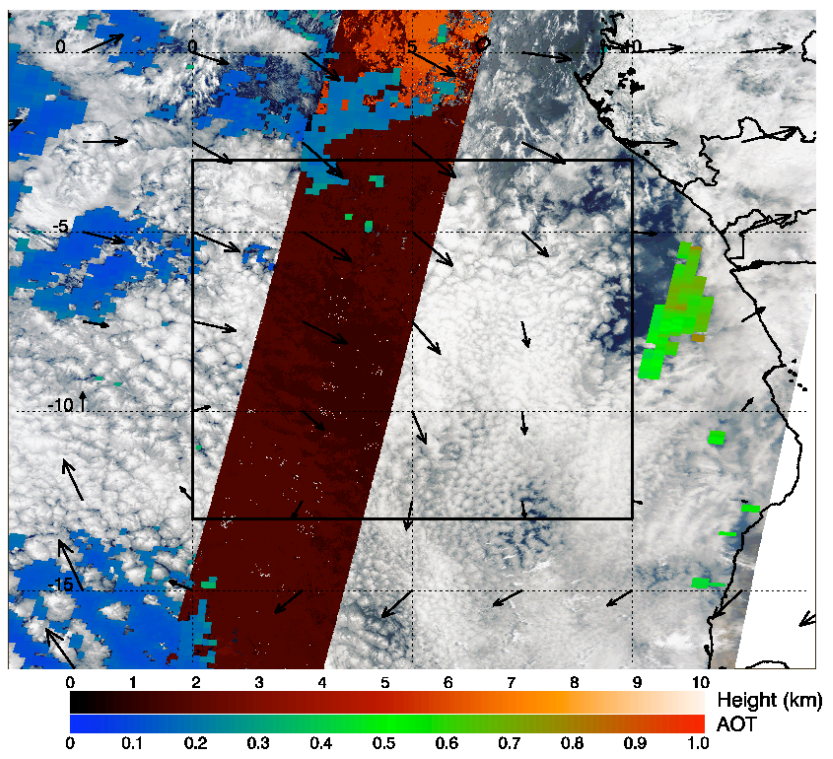

Fig. 13. Terra MODIS three band overlay for the South Eastern Atlantic off Africa on 30 September 2004. Note the thick low-level stratus field present over most of the study domain.

On 30 September 2004 MISR observed cloud-heights only up to $2 \mathrm{~km}$, while biomass burning aerosols are likely present even higher in the atmosphere as the TOMS-AI value for this day is 1.5 (Fig. 13, Table 3). In this example a large stratus deck exists over most of the region with an average CTP of $860 \mathrm{hPa}$. For this day, the anthropogenic AIE is $-3.3 \mathrm{Wm}^{-2}$ though vertical motion is weak throughout the atmospheric column (Fig. 10). If these AIE values are a reflection of actual microphysical interactions, then significant aerosol concentrations should also be present near the surface. Experiments during the SAFARI campaign and CALIPSO satellite observations noted significant aerosol concentrations from biomass burning are frequently trapped in a stable layer at or above $3 \mathrm{~km}$ a.s.l., allowing for transport well into the central Atlantic while aerosols below the boundary layer tended not to travel as far (Garstang et al., 1996). However, the region of study is close enough to the source region that aerosols at both levels are present. Also, the presence of the low-level stratus deck throughout the last half of the year while also noting that aerosols are also present near this layer has been obesrved. Both this, and the case study example described above support the notion that AIE does occur in AF, but that the cloud layer is generally quite low to the surface and that primarily boundary layer aerosols are responsible. As a result, vertical motion and other atmospheric conditions above this layer are not as important as in other regions.

\subsubsection{Western North Atlantic (WA)}

Another region consisting of aerosols produced from anthropogenic pollution sources is present off the eastern coast of the United States. In the western Atlantic, AOT and DCF is maximized in JJA in association with seasonal variations in industrial pollution and atmospheric transport patterns. However, overall upward vertical motion in JJA is relatively weak and shows no low level maximum like the Arabian Sea (Fig. 7b). As a result, most aerosols are trapped in the boundary layer below $1.5 \mathrm{~km}$ (Table $1 \mathrm{~b}$ ). The correlation between AOT and $R_{c}$ is low during the summer months, still AIE is greatest in JJA with an average value of $-0.89 \mathrm{Wm}^{-2}$ compared to $-0.48 \mathrm{Wm}^{-2}$ in DJF (Table 1b, Fig. 6e), with the majority of AIE being from the anthropogenic component. Cloud cover and cloud thickness on the other hand are maximized during the winter months though CTP remains approximately constant (Table $2 \mathrm{~b}$ ), in response to low-pressure systems that propagate through this region. Comparing the thick cloud vs. thin cloud sample shows that total AIE is three times larger in the thick cloud sample (Table 2a), with most of that sample originating from summer data. Even with the inherent uncertainties present using this method, AIE values derived here exceed those required to be considered physically significant. In addition, a similar certainty exists for the difference in thin vs. thick clouds, though upward motion only appears to increase AIE in the thick cloud sample. Thus, for this region it appears that conditions favorable for thicker and more persistent clouds are indeed important to the magnitude of AIE, more so than just the aerosol concentration itself, consistent with the observations by Bulgin et al. (2008). The concentration of dust aerosols within this region remains small compared to the anthropogenic component and as a result, dust AIE remains small.

\subsubsection{South Indian Ocean}

In a more pristine environment such as in the Southern Indian Ocean, little variability exists in the overall atmospheric conditions (Fig. 4f). Maximum relative humidity occurs between $850 \mathrm{hPa}$ and the surface and vertical velocities remain low (Fig. 7). Overall, cloud fraction and COT also do not vary by more than $\pm 10 \%$ and \pm 0.7 respectively, indicating that the primary cloud mode is maritime stratus with nearly $80 \%$ of the clouds having a $\mathrm{LWP}>20 \mathrm{gm}^{-2}$.

Seasonal variations in AOT do exist and correspond to small changes in the dust and anthropogenic aerosol concentrations. The contributions from dust and anthropogenic aerosols account for $\sim 40 \%$ of the total AOT, but recall that AOT in this region is the lowest for the six regions studied here $(\tau=0.13)$. Maximum aerosol height does not vary much and generally remains below $1.5 \mathrm{~km}$, or within the boundary layer (Table 1b). Dust and anthropogenic direct aerosol radiative effects vary according to the changes in their concentration, but only reach a maximum of $-1.5 \mathrm{Wm}^{-2}$ (Fig. 6f). Variations in AIEs are less clear. Both anthropogenic and dust AIEs are consistently negative, but almost always less than $-1.0 \mathrm{Wm}^{-2}$. As with several other regions, AIE is significantly greater for the thick cloud sample where upward vertical motion is greatest $\left(-0.85 \mathrm{Wm}^{-2}\right)$. 
The "anthropogenic" component of AIE is greater than that associated with "dust". However, the uncertainties in aerosol classification are magnified for such low AOT values. It is possible what some of the "anthropogenic" aerosols are actually fine mode DMS whereas some of the "dust" may actually be sea-salt. Fine mode aerosols, whether anthropogenic or natural in origin appear to be very important to AIE as this is the only region where FMF actually becomes greater as cloud fraction increase (Fig. 2c). This is consistent with Vallina (2006) who noted that changes in fine mode aerosols were key to changes in AOT over pristine ocean regions and that the fine mode aerosols present dominate $\mathrm{CCN}$. It is important to note that the direct and indirect effects of sea-salt aerosols are not shown. Maritime AOT likely accounts for at least one half of the total AOT, and as a result would have direct and indirect effects on the order of the dust + anthropogenic values listed here, assuming they are acting as $\mathrm{CCN}$.

\section{Conclusions}

It is clear from this long term, regional analysis that atmospheric conditions and aerosol layer height have comparable importance to aerosol concentrations when determining the presence of aerosol indirect effects. The following are the significant conclusions from this study.

1) While a clear relationship between AOT and direct radiative effect exists for each region, AOT alone is not necessarily a good predictor of AIE. For example, the greatest total AIE $\left(-0.73 \mathrm{Wm}^{-2}\right)$ is observed in IO, where AOT only averaged 0.13 . In contrast, EA contained the highest average AOT (0.39), but actually has a slightly positive average total AIE values $\left(+0.1 \mathrm{Wm}^{-2}\right)$. Similarly, region BB with an average AOT of 0.27 also failed to produce any significant AIE values. Thus, it is clear that for many of the regions analyzed in this study, other factors besides total aerosol concentrations are playing an important part in AIE.

2) One such factor is the importance of vertical velocity, specifically, the presence of upward motion that increases the favorability of the environment towards cloud formation, enhancing AIE. In three out of the six regions studied (AS, IO, WA), AIEs are significantly greater when upward vertical motion at $850 \mathrm{hPa}$ and cloud thickness is greatest. AIE is observed for thinner, clouds under less favorable conditions, but its magnitude is always less. In AF, vertical velocity at $850 \mathrm{hPa}$ is not since important as clouds primarily consisted of a low-level, thin, stratus deck that exist below the $850 \mathrm{hPa}$ layer when AOT was maximized. Other exceptions to this rule occurred in the $\mathrm{BB}$, where AIE is consistently small and EA, where AIE is often positive. In EA, the lack of favorable atmospheric conditions coupled with the presence of mostly non-hygroscopic aerosols (dust) limits the potential for AIE. Also the absorbing nature of dust aerosols suggests a more important role for the semi-direct effect than for the other regions examined here.

3) In BB, significant cloud cover is present at times and is sometimes thick (LWP $>20 \mathrm{gm}^{-2}$ ) and associated with upward vertical motion, but AIE remains small. Using vertical profiles of vertical velocity, CALIPSO, and an example of MISR aerosol and cloud-layer height data, it appears that clouds layers do not correspond with the levels of maximum aerosol concentration, thus limiting the AIE. In other regions where AIE is occurring, AS, WA, and IO, a much better correspondence between aerosol and cloud layer height exists, especially if one assumes that aerosols are well mixed below the maximum observed layer height. These observations emphasize the importance of vertical profiles of aerosol and cloud layers when estimating AIE and interpreting the physical mechanisms contributing to it.

4) Anthropogenic AIE (i.e. AIE resulting from fine mode aerosols) is greater than AIE from dust aerosols in 3 out of 4 regions where average AIE was consistently non-zero (IO, $\mathrm{WA}, \mathrm{AF})$. In these three regions, fine mode aerosols from industrial pollution and/or biomass burning is the predominate aerosol type, which happen to be aerosols that act as excellent $\mathrm{CCN}$ under the right conditions. The exception to this rule occurs in AS, where dust AIE is double that of anthropogenic AIE $\left(-0.23\right.$ vs. $\left.-0.10 \mathrm{Wm}^{-2}\right)$ and especially large during the summer months when dust AOT is greatest (0.11). However, dust aerosols are likely being coated with sulfates to some extent based on the also high anthropogenic AOT (0.16), which has been verified by studies such as Levin et al. (1996), Seinfeld and Pandis (1998), and Satheesh et al. (2006). Dust aerosols are the primary contributor to total AOT in EA, but they do not become coated with soluble material and are not necessarily co-located with cloud layer height. Given the absorbing nature of dust aerosols, these observations suggest a greater importance for semi-direct effects.

Given the uncertainties inherent in satellite derived aerosol and cloud retrievals, some caution needs to be exercised when interpreting the results. Using the change in magnitude of $R_{c}$ as a function of AOT as a guide, the resulting AIE values are considered significant and a result of physical causes. Recall that FMF decreased approximately 15\% between clear and near-cloudy skies (except in EA and IO), which is consistent with hygroscopic aerosols increasing in size in high humidity conditions near clouds. Thus, if the difference in the AOT $-R_{c}$ relationship that falls below this $15 \%$ value AIE cannot be considered significant. Table $2 \mathrm{~d}$ shows that the differences are indeed larger for both thin and thick clouds, increasing the confidence of the results presented here. Similarly, differences between dust and anthropogenic AIE are significant indicating the importance of aerosol type relative to the occurrence to aerosol - cloud interactions. 
Acknowledgements. This research is supported by NASA's Radiation sciences, Interdisciplinary sciences, an EOS grant, and ACMAP programs. The CERES SSF data that contains the merged MODIS and CERES and the MISR data were obtained through the NASA Langley Distributed Active Archive Systems. We would like to also recognize Aaron Naegar for calculating CALIPSO aerosol layer heights for each region.

Edited by: T. Garrett

\section{References}

Ackerman, A. S., Toon, O. B., Stevens, D. E., Heymsfield, A. J., Ramanathan, V., and Welton, E. J.: Reduction of tropical cloudiness by soot, Science, 288, 1042-1047, 2000.

Ackerman, A. S., Toon, O. B., Stevens, D. E., and Coakley Jr., J. A.: Enhancement of cloud cover and suppression of nocturnal drizzle in stratocumulus polluted by haze, Geophys. Res. Lett., 30, L1381, doi:10.1029/2002GL016634, 2003.

Albrecht, B.: Aerosols, Cloud Microphysics, and Fractional Cloudiness, Science, 245, 1227-1230, 1989.

Anderson, T. L., Charlson, R. J., Schwartz, S. E., Knutti, R., Boucher, O., Rhode, H., and Heintzenberg, J.: Climate forcing by aerosols - a hazy picture, Science, 300, 1103-1104, 2003.

Andreae, M. O. and Rosenfeld, D.: Aerosol-cloud-precipitation interactions, Part 1, The nature and sources of cloud-active aerosols, Earth Sci. Rev., 89, 13-41, 2008.

Andreae, M. O.: Correlation between cloud condensation nuclei concentration and aerosol optical thickness in remote and polluted regions, Atmos. Chem. Phys., 9, 543-556, 2009,

http://www.atmos-chem-phys.net/9/543/2009/.

Avey, L., Garrett, T. J., and Stohl A.: Evaluation of the aerosol indirect effect using satellite, tracer transport model, and aircraft data from the International Consortium for Atmospheric Research on Transport and Transformation, 112, D10S33, doi:10.1029/2006JD007581, 2007.

Bellouin, N., Boucher, O., Haywood, J., and Reddy, M. S.: Global estimate of aerosol direct radiative forcing from satellite measurements, Nature, 438, 1138-1141, doi:10.1038/nature04348, 2005.

Bellouin, N., Jones, A., Haywood, J., and Christopher, S. A.: Updated estimate of aerosol direct radiative forcing from satellite observations and comparison against the Hadley Centre climate model, J. Geophys. Res., 113, D10205, doi:10.1029/2007JD009385, 2008.

Bennartz, R.: Global assessment of marine boundary layer cloud droplet number concentration from satellite, J. Geophys. Res., 112, D02201, doi:10.1029/2006JD007547, 2007.

Boucher, O. and Lohmann, U.: The sulfate - CCN - cloud albedo effect - a sensitivity study with two general circulation models, Tellus, 47B, 281-300, 1995.

Borg, L. A. and Benartz, R.: Vertical structure of stratiform marine boundary layer clouds and its impact on cloud albedo, Geophys. Res. Lett., 34, L05807, doi:10.1029/2006GL028713, 2007.

Brenguier, J.-L., Pawlowska, H., and Schuller, L.: Cloud microphysical and radiative properties for parameterization and satellite monitoring of the indirect effect of aerosol on climate, J. Geophys. Res., 108, doi:10.1029/2002JD002682, 2003.
Breon, F. M., Tanré, D., Generosol, S., et al.: Aerosol effect on cloud droplet size monitored from satellite, Science, 295, 834838, 2002.

Bulgin, C. E., Palmer, P. I., Thomas, G. E., Arnold, C. P. G., Campmany, E., Craboni, E., Grainger, R. G., Poulsen, C., Siddans, R., and Lawrence, B. N.: Regional and seasonal variations of the Twomey indirect effect as observed by the ATSR-2 satellite instrument, Geophys. Res. Lett., 35, L02811, doi:10.1029/2007GL031394, 2008.

Christopher, S. A. and Jones, T. A.: Sample bias correction for estimating Cloud Free Aerosol Shortwave Radiative Effects over Global Oceans, IEEE T. Geosci. Remote, 46, 1728-1732, 2008.

Chylek, P., Dubey, M. K., Lohmann, U., Ramanathan, V., Kaufman, Y. J., Lesins, G., Hudson, J., Altmann, G., and Olsen, S.: Aerosol indirect effect over the Indian Ocean, Geophys. Res. Lett., 33, L06806, doi:10.1029/2005GL025397, 2006.

Coakley, J. A. and Walsh, C. D.: Limits to the Aerosol Indirect Radiative Effect Derived from Observations of Ship Tracks, J. Atmos. Sci., 59, 668-680, 2002.

DeMott, P. J., Sassen, K., Poellot, M. R., Baumgardner, D., Rodgers, D. C., Brooks, S. D., Prenni, A. J., and Kreidenweis, S. M.: African dust aerosols as atmospheric ice nuclei, Geophys. Res. Lett., 30, 1732, doi:10.1029/2003GL017410, 2003.

Duesk U., Frank, G. P., Hildebrandt, L., et al.: Size matters more than chemistry for cloud-nucleating ability of aerosol particles, Science, 312, 1375-1378, 2006.

Dunion, J. P. and Velden, C. S.: The impact of the Saharan air layer on Atlantic tropical cyclone activity, B. Am. Meteorol. Soc., 85, 353-365, 2004.

Feingold, G., Remer, L. A., Ramaprasad, J., and Kaufman, Y. J.: Analysis of smoke impact on clouds in Brazilian biomass burning regions: An extension of Twomey's approach, J. Geophys. Res., 106(D19), 22907-22922, 2001.

Feingold, G.: Modeling of the first indirect effect: Analysis of measurement requirements, Geophys. Res. Lett., 30(6), doi:10.1029/2003GL017967, 2003.

Feingold, G., Eberhard, W. L., Veron, D. E., and Previdi, M.: First measurements of the Twomey indirect effect using ground-based remote sensors, Geophys. Res. Lett., 30(6), doi:10.1029/2003GL016633, 2003.

Forster, P., Ramaswamy, V., Artaxo, P., Berntsen, T. R., Betts, D. W., Fahey, J. Haywood, J., Lean, D. C., Lowe, G., Myhre, J., Nganga, R., Prinn, G., Raga, M. Schulz, and Van Dorland, R.: Changes in Atmospheric Constituents and in Radiative Forcing, in: Climate Change 2007: The Physical Science Basis. Contribution of Working Group I to the Fourth Assessment Report of the Intergovernmental Panel on Climate Change, edited by: Solomon, S., Qin, D., Manning, M., Chen, Z., Marquis, M., Averyt, K. B., Tignor, M., and Miller, H. L., Cambridge University Press, Cambridge, United Kingdom and New York, NY, USA, 2007.

Garstang, M., Tyson, P. D., Swap, R., Edwards, M., Kallberg, P., and Lindesay, J. A.: Horizontal and vertical transport of air over southern Africa, J. Geophys. Res., 101, 23721-23736, 1996.

Han, Q. Y., Rossow, W. B., and Lacis, A. A.: Near-global survey of effective droplet radii in liquid water clouds using ISCCP data, J. Climate, 7, 465-497, 1994.

Han, Q., Rossow, W. B., Chou, J., and Welch, R. M.: Global survey of the relationships of cloud albedo and liquid water path with 
droplet size using ISCCP, J. Climate, 11, 1516-1528, 1998.

Heintzenberg, J., Charlson, R. J., Clarke, A. D., et al.: Measurements and modeling of aerosol single-scattering albedo: Progress, problems, and prospects, Contrib. Atmos. Phys., 70, 249-263, 1997.

Hsu, N. C., Herman, J. R., and Weaver, C. J.: Determination of radiative forcing of Saharan dust using combined TOMS and ERBE data, J. Geophys. Res., 105, 20649-20661, 2000.

Jones, A., Roberts, D. L., and Slingo, A.: A climate model study of indirect radiative forcing by anthropogenic sulphate aerosols, Nature, 370, 450-453, 1994.

Jones, T. A. and Christopher, S. A.: MODIS derived fine mode fraction characteristics of marine, dust, and anthropogenic aerosols over the ocean, constrained by GOCART, MOPITT, and TOMS, J. Geophys. Res., 12, D22204, doi:10.1029/2007JD008974, 2007.

Jones, T. A. and Christopher, S. A.: Seasonal variation in satellite derived effects of aerosols on clouds in the Arabian Sea, J. Geophys. Res., 113, D09207, doi:10.1029/2007JD009118, 2008.

Kalnay, E., Kanamitsu, M., Kistler, R., et al.: The NCEP/NCAR 40-year reanalysis project, B. Am. Meteorol. Soc., 77, 437-471, 1996.

Kaufman, Y. J. and Fraser, R. S.: The effect of smoke particles on clouds and climate forcing, Science, 277, 1636-1639, 1997.

Kaufman, Y. J., Koren, I., Remer, L. A., Rosenfeld, D., and Rudich, Y.: The effect of smoke, dust, and pollution, aerosol on shallow cloud development over the Atlantic Ocean, Proc. Natl. Acad. Sci., 102(32), 11207-11212, 2005a.

Kaufman, Y. J., Koren, I., Remer, L. A., Tanré, D., Ginoux, P., and Fan, S.: Dust transport and deposition observed from the Terra-Moderate Resolution Imaging Spectroradiometer (MODIS) spacecraft over the Atlantic Ocean, J. Geophys. Res., D10S12, doi:10.1029/2003JD004436, 2005b.

Kaufman, Y. J., Boucher, O., Tanre, D., Chin, M., Remer, L. A., et al.: Aerosol anthropogenic component estimated from satellite data, Geophys. Res. Lett., 32, L17804, doi:10.1029/2005GL023125, 2005c.

Koren, I., Remer, L. A., Kaufman, Y. J., Rudich, Y., and Martins, J. V.: On the twilight zone between clouds and aerosols, Geophys. Res. Lett., 34, L08805, doi:10.1029/2007GL029253, 2007.

Koren, I., Martins, J. V., Remer, L. A., and Afargan, H.: Smoke invigoration versus inhibition of clouds over the Amazon, Science, 321, 946-949, 2008.

Lee, S. S., Penner, J. E., and Saleeby, S. M.: Aerosol effects on liquid-water path of thin stratocumulus clouds, J. Geophys. Res., 114, D07204, doi:10.1029/2008JD010513, 2009.

Levin, Z., Ganor, E., and Gladstein, V.: The effects of desert particles coated with sulfate on rain formation in the eastern Mediterranean, J. Appl. Meteor., 35, 1511-1523, 1996.

Lin, J. C., Matsui, T., Pielke Sr., R. A., and Kummerow, C.: Effects of biomass burning derived aerosols on precipitation and clouds in the Amazon Basin: a satellite-based empirical study, J. Geophys. Res., 111, D19204, doi:10.1029/2005JD006884, 2006.

Lindesay, J. A., Andreae, M. O., Goldammer, J. G., Harris, G., Annegarn, H. J., Garstang, M., Scholes, R. J., and van Wilgen, B. W.: International Geosphere-Biosphere Programme/International Global Atmospheric Chemistry SAFARI92 field experiment: Background and overview, J. Geophys. Res., 101, 23521-23530, 1996.
Loeb, N. G. and Manalo-Smith, N.: Top-of-atmosphere direct radiative effect of aerosols over global oceans from merged CERES and MODIS observations, J. Climate, 18, 3506-3526, 2005.

Lohmann, U. and Feichter, J.: Global indirect aerosol effects: A review, Atmos. Chem. Phys., 5, 715-737, 2005, http://www.atmos-chem-phys.net/5/715/2005/.

Lohmann, U. and Lesins, G.: Comparing continental and oceanic cloud susceptibilities to aerosols, Geophys. Res. Lett., 30, doi:10.1029/2003GL017828, 2003.

Mauger, G. S. and Norris, J. R.: Meteorological bias in satellite estimates of aerosol-cloud relationships, Geophys. Res. Lett., 34, L16824, doi:10.1029/2007GL029952, 2007.

Marshak, A., Wen, G., Coakley, J. A., Remer, L. A., Loeb, N. G., and Cahalan, R. F.: A simple model for the cloud adjacency effect and the apparent bluing of aerosols near clouds, J. Geophys. Res., 113, D14S17, doi:10.1029/2007JD009196, 2008.

Matheson M. A., Coakley Jr, J. A., and Tahnk, W. R.: Aerosol and cloud property relationships for summertime stratiform clouds in the northeastern Atlantic from Advanced Very High Resolution Radiometer observations, J. Geophys. Res., 110, D24204, doi:10.1029/2005JD006165, 2005.

Matsui, T., Masunaga, H., Kreidenweis, S. M., Pielke Sr., R. A., Tao, W.-K., Chin, M., and Kaufman, Y. J.: Satellite based assessment of marine low cloud variability associated with aerosol, atmospheric stability, and the diurnal cycle, J. Geophys. Res., D17204, doi:10.1029/2005JD006097, 2006.

Minnis, P., Young, D. F., Sun-Mack, S., Heck, P. W., Doelling, D. R., and Trepte, Q.: CERES Cloud Property Retrievals from Imagers on TRMM, Terra, and Aqua., Proc. SPIE 10th International Symposium on Remote Sensing: Conference on Remote Sensing of Clouds and the Atmosphere VII, Barcelona, Spain, 8-12 September, 37-48, 2003.

Moroney, C., Davies, R., and Muller, J.-P.: MISR stereoscopic image matchers: Techniques and results, IEEE T. Geosci. Remote, 40, 1547-1559, 2002.

Nakajima, T., King, M. D., and Spinhirne, J. D.: Determination of the optical thickness and effective particle radius of clouds from reflected solar radiation measurements. Part II: Marine stratocumulus observations, J. Atmos. Sci., 48, 728-750, 1991.

Patra, P. K., Behera, S. K., Herman, J. R., Maksyutov, S., Akimoto, H., and Yamagata, T.: The Indian summer monsoon rainfall: interplay of coupled dynamics, radiation, and cloud microphysics, Atmos. Chem. Phys., 5, 2181-2188, 2005, http://www.atmos-chem-phys.net/5/2181/2005/.

Penner, J. E., Dong, X., and Chen, Y.: Observational evidence of a change in radiative forcing due to the indirect aerosol effect, Nature, 427, 231-234, 2004.

Parungo, F., Kopcewicz, B., Nagamoto, C., Schnell, R., Sheridan, P., Zho, C., and Harris, J.: Aerosol particles in the Kuwait oil fire plumes: Their morphology, size distribution, chemical composition, transport, and potential effect on climate, J. Geophys. Res., 97, 15867-15882, 1992.

Platnick, S., King, M. D., Ackerman, S. A., Menzel, W. P., Baum, B. A., Riédi, J. C., and Frey, R. A.: The MODIS Cloud Products: Algorithms and Examples from Terra, IEEE T. Geosci. Remote, 41, 459-473, 2003.

Quaas, J., Boucher, O., and Breon, F.-M.: Aerosol indirect effects in POLDER satellite data and the Laboratoire de Meteorologie Dynamique-Zoom (LMDZ) general circulation model, 
J. Geophys. Res., 109, doi:10.1029/2003JD004317, 2004.

Quaas, J., Boucher, O., Bellouin, N., and Kinne, S.: Satellite-based estimate of the direct and indirect aerosol climate forcing, J. Geophys. Res., 113, doi:10.1029/2007JD008962, 2008.

Ramana M. V. and Ramanathan, V.: Abrupt transition from natural to anthropogenic aerosol radiative forcing: Observations at the ABC-Maldives Climate Observatory, J. Geophys. Res., 111, D20207, doi:10.1029/2006JD007063, 2006.

Ramanathan, V., Crutzen, P. J., Kiehl, J. T., and Rosenfeld, D.: Indian Ocean Experiment: An integrated analysis of the climate forcing and effects of the great Indo-Asian haze, J. Geophys. Res., 106(22), 28371-28398, 2001.

Redemann, J., Zhang, Q., Russell, P. B., Livingston, J. M., and Remer, L. A.: Case studies of aerosol remote sensing in the vicinity of clouds, J. Geophys. Res., 114, D06209, doi:10.1029/2008JD010774, 2009.

Reid, J. S., Eck, T. F., Christopher, S. A., Hobbs, P. V., and Holben, B. N.: Use of the Ångström exponent to estimate the variability of optical and physical properties of aging smoke particles in Brazil, J. Geophys. Res., 104, 27473-27489, 1999.

Remer, L. A. and Kaufman, Y. J.: Aerosol direct radiative effect at the top of the atmosphere over cloud free ocean derived from four years of MODIS data, Atmos. Chem. Phys., 6, 237-253, 2006, http://www.atmos-chem-phys.net/6/237/2006/.

Satheesh, S. K., Moorthy, K. K., Kaufman, Y. J., and Takemura, T.: Aerosol optical depth, physical proper ties and radiative forcing over the Arabian Sea, Meteorol, Atmos. Phys., 91, 45-62, 2006.

Schulz, M., Textor, C., Kinne, S., Balkanski, Y., Bauer, S., Berntsen, T., Berglen, T., Boucher, O., Dentener, F., Grini, A., Guibert, S., Iversen, T., Koch, D., Kirkevåg, A., Liu, X., Montanaro, V., Myhre, G., Penner, J., Pitari, G., Reddy, S., Seland, $\varnothing$., Stier, P., and Takemura, T.: Radiative forcing by aerosols as derived from the AeroCom present-day and pre-industrial simulations, Atmos. Chem. Phys., 6, 5225-5246, 2006, http://www.atmos-chem-phys.net/6/5225/2006/.

Schwartz, S. E., Harshvardhan, and Benkovitz, C. M.: Influence of anthropogenic aerosol on cloud optical depth and albedo shown by satellite measurements and chemical transport modeling, Proc. Nat. Acad. Sci. US., 99, 1784-1789, 2002.

Seinfeld, J. H. and Pandis, S. N.: Atmospheric Chemistry and Physics: From Air Pollution to Climate Change, John Wiley, Hoboken, N. J. 1998.
Sinha, P., Hobbs, P. V., Yokelson, R. J., Blake, D. R., Gao, S., and Kirchstetter, T. W.: Distributions of trace gases and aerosols during the dry biomass burning season in southern Africa, J. Geophys. Res., 108(D17), 4536, doi:10.1029/2003JD003691, 2003.

Snider, J. R., Guibert, S., Brenguier, J.-L., and Putland, J.-P.: Aerosol activation in marine stratocumulus clouds: 2. Kohler and parcel theory closure studies, J. Geophys. Res., 108(D15), 8629, doi:10.1029/2002JD002692, 2003.

Su, W., Schuster, G. L., Loeb, N. G., Rodgers, R. R., Ferrare, R. A., Hostetler, C. A., Hair, J. W., and Obland, M. D.: Aerosol and cloud interaction observed from high spectral resolution lidar, J. Geophys. Res., 113, D24202, doi:10.1029/2008JD010588, 2008.

Torres, O., Bhartia, P. K., Herman, J. R., Sinyuk, A., Ginoux, P., and Holben, B. N.: A long-term record of aerosol optical depth from TOMS observations and comparison to AERONET measurements, J. Atmos. Sci., 59(3), 398-413, 2002.

Turner, D. D., Vogelmann, A. M., Austin, R. T.: Thin liquid water clouds: Their importance and our challenge, B. Am. Meteor. Soc., 88, 177-190, 2007.

Twomey, S. A.: The influence of pollution on the shortwave albedo of clouds, J. Atmos. Sci., 34, 1149-1152, 1977.

Vaughan, M., Young, S., Winker, D., Powell, K., Omar, A., Liu, Z., Hu, Y., and Hosteler, C.: Fully automated analysis of spacebased lidar data: an overview of CALIPSO retrieval algorithms and data products, SPIE, 5575, 16-30, 2004.

Vallina, S. M., Simo, R., and Gasso, S.: What controls CCN seasonality in the Southern Ocean? A statistical analysis based on satellite derived chlorophyll and $\mathrm{CCN}$ and model estimated $\mathrm{OH}$ radical and rainfall, Global Biogeochem. Cy., 20, GB1014, doi:10.1029/2005GB002597, 2006.

Wang, B. L., Ho, Y., Zhang, and Lu, M.-M.: Definition of South China Sea Monsoon onset and commencement of the East Asia Summer Monsoon., J. Climate, 17, 669-710, 2004.

Wen, G., Marshak, A., and Cahalan, R. F.: Impact of 3-D clouds on clear sky reflectance and aerosol retrieval in a biomass burning region of Brazil, IEEE Geosci. Remot. S., 3, 169-172, 2006.

Wood, R. and Hartmann, D. L.: Spatial variability of liquid water path in marine low clouds: Part 1. Probability distribution and mesoscale cellular scales, J. Climate., 19, 1748-1764, 2006.

Yuan, T., Li, Z., Chang, F. L., Vant-Hull, B., and Rosenfeld, D.: Increase of cloud droplet size with aerosol optical depth: An observation and modeling study, J. Geophys. Res., 113, D04201, doi:10.1029/2007JD008632, 2008. 